\title{
Loss of Homeostasis in the Direct Pathway in a Mouse Model of Asymptomatic Parkinson's Disease
}

\author{
Mariela V. Escande, ${ }^{1}$ Irene R. E. Taravini, ${ }^{2,3}$ Camila L. Zold, ${ }^{1}$ J Juan E. Belforte, ${ }^{1 *}$ and M. Gustavo Murer ${ }^{1 *}$ \\ ${ }^{1}$ Systems Neuroscience Group, IFIBIO Bernardo Houssay, CONICET and Universidad de Buenos Aires, Department of Physiology and Biophysics, \\ University of Buenos Aires School of Medicine, Buenos Aires, Argentina 1121, ${ }^{2}$ Experimental Parkinsonism Group, ININFA, CONICET, and University of \\ Buenos Aires, Buenos Aires, Argentina 1121, and 'Experimental Neurobiology Laboratory, University of Entre Ríos, Concepción del Uruguay, Entre Ríos, \\ Argentina 2820
}

The characteristic slowness of movement in Parkinson's disease relates to an imbalance in the activity of striatal medium spiny neurons (MSNs) of the direct (dMSNs) and indirect (iMSNs) pathways. However, it is still unclear whether this imbalance emerges during the asymptomatic phase of the disease or if it correlates with symptom severity. Here, we have used in vivo juxtacellular recordings and transgenic mice showing MSN-type-specific expression of fluorescent proteins to examine striatal imbalance after lesioning dopaminergic neurons of the substantia nigra. Multivariate clustering analysis of behavioral data discriminated 2 groups of dopamine-lesioned mice: asymptomatic ( $42 \pm 7 \%$ dopaminergic neuron loss) and symptomatic ( $85 \pm 5 \%$ cell loss). Contrary to the view that both pathways have similar gain in control conditions, dMSNs respond more intensely than iMSNs to cortical inputs in control animals. Importantly, asymptomatic mice show significant functional disconnection of dMSNs from motor cortex without changes in iMSN connectivity. Moreover, not only the gain but also the timing of the pathways is altered in symptomatic parkinsonism, where iMSNs fire significantly more and earlier than dMSNs. Therefore, cortical drive to dMSNs decreases after partial nigrostriatal lesions producing no behavioral impairment, but additional alterations in the gain and timing of iMSNs characterize symptomatic rodent parkinsonism.

Key words: 6-OHDA; functional connectivity; in vivo electrophysiology; medium spiny neurons; striatum

Significance Statement

Prevailing models of Parkinson's disease state that motor symptoms arise from an imbalance in the activity of medium spiny neurons (MSNs) from the direct (dMSNs) and indirect (iMSNs) pathways. Therefore, it is hypothesized that symptom severity and the magnitude of this imbalanced activity are correlated. Using a mouse model of Parkinson's disease, we found that behaviorally undetectable nigrostriatal lesions induced a significant disconnection of dMSNs from the motor cortex. In contrast, iMSNs show an increased connectivity with the motor cortex, but only after a severe dopaminergic lesion associated with an evident parkinsonian syndrome. Overall, our data suggest that the lack of symptoms after a partial dopaminergic lesion is not due to compensatory mechanisms maintaining the activity of both striatal pathways balanced.

\section{Introduction}

Parkinson's disease is caused by the progressive loss of dopaminergic neurons of the substantia nigra that preferentially project to the dorsal striatum. The slowness of movement that character-

Received Feb. 2, 2015; revised March 14, 2016; accepted March 20, 2016.

Author contributions: M.V.E., C.L.Z., J.E.B., and M.G.M. designed research; M.V.E., I.R.E.T., and C.L.Z. performed research; M.V.E., J.E.B., and M.G.M. analyzed data; C.L.Z., J.E.B., and M.G.M. wrote the paper.

This work was supported by Fondo para la Investigación Científica y Tecnológica (Grant PICT-2013-1523) and the University of Buenos Aires (Grant UBACYT-2014-249BA). We thank Graciela Ortega for excellent technical assistance.

The authors declare no competing financial interests.

*J.E.B. and M.G.M. contributed equally to this work.

Correspondence should be addressed to Mariela Escande, IFIBIO Houssay, 2155 Paraguay St, Buenos Aires (1121), Argentina. E-mail: mvescande@gmail.com.

DOI:10.1523/JNEUROSCI.0492-15.2016

Copyright $\odot 2016$ the authors $\quad 0270-6474 / 16 / 365686-13 \$ 15.00 / 0$ izes the disease is attributed to an imbalance in the activity of the direct and indirect basal ganglia pathways. These pathways originate from different classes of striatal medium spiny neurons (MSNs), the functional roles of which in motor control are still debated (Frank et al., 2007; Cui et al., 2013; Schmidt et al., 2013; Tecuapetla et al., 2014; Sippy et al., 2015). The dominance of the indirect pathway in Parkinson's disease could be due to a relative increase in the resting activity (DeLong, 1990; Kravitz et al., 2010) and/or response to motor cortex inputs (Mink, 1996; Hikosaka et al., 2000; Frank et al., 2007) of indirect pathway MSNs (iMSNs). Moreover, an earlier response of iMSNs to cortical inputs might impede signals conveyed by direct pathway MSNs (dMSNs) to gain control of basal ganglia output neurons (Schmidt et al., 2013). According to these views, the functional imbalance between the two pathways should be related to symptom severity. 
However, no study has yet correlated the activity of dMSNs and iMSNs with the extent of nigrostriatal degeneration and the resulting behavioral impairment in animal models of Parkinson's disease.

Parkinson's disease is diagnosed after a long asymptomatic phase that ends when $>50 \%$ of the dopaminergic neurons have degenerated (Bernheimer et al., 1973; Bezard et al., 2003). The absence of symptoms after partial nigrostriatal lesions is usually attributed to compensations occurring in the remaining dopaminergic cells (Zigmond, 1997). However, whether dopaminergic compensations suffice to maintain a normal activity in MSNs after partial nigrostriatal lesions remains unknown. In addition, even if dopamine modulation of striatal circuits declined concomitantly with nigrostriatal degeneration, MSN compensations could prevent the striatal activity imbalance and symptom appearance (Bezard et al., 2003; Fieblinger et al., 2014). Therefore, it is yet to be determined whether the activity balance between dMSNs and iMSNs is maintained after partial nigrostriatal degeneration.

In the present study, we lesioned dopaminergic neurons of the substantia nigra in transgenic mice expressing fluorescent proteins in specific MSN subtypes (Shuen et al., 2008). Unsupervised multivariate clustering analysis of behavioral data allowed discrimination of asymptomatic and symptomatic animals. We studied the activity of identified dMSNs and iMSNs in lesioned and control groups using juxtacellular recordings in anesthetized animals and evaluated their response to electrical stimulation of the motor cortex. Remarkably, MSNs show compensatory changes in membrane excitability that would oppose, rather than promote, the striatal activity imbalance (Fieblinger et al., 2014). Therefore, in vivo responses of MSNs to cortical inputs after dopaminergic lesion cannot be easily predicted from changes in their membrane properties. In addition, because thalamostriatal connectivity differs in several aspects from corticostriatal connectivity (Smith et al., 2014) and to assess whether both pathways are similarly affected by the dopaminergic lesion, we also recorded the response of dMSNs and iMSNs to thalamic stimulation.

\section{Materials and Methods}

Animals

Drd 1a-tdTomato (line 5) BAC-transgenic mice that express the red fluorescent protein tdTomato under the control of a Drdla promoter (Shuen et al., 2008) were generously provided by Nicole Calakos (Duke University). Hemizygous BAC-transgenic mice were backcrossed with wildtype C57BL/6 mice for four to five generations to generate the hemizygous animals used for experiments. Pups (1-4 d old) were observed with a fluorescent lamp and selected if red fluorescence was seen in their brain hemispheres. Female mice were used for electrophysiological recordings at 16-32 weeks of age. All procedures were in accordance with institutional (Institutional Animal Care and Use Committee of the School of Medicine, University of Buenos Aires, 2598/13) and government (National Food Safety and Quality Service, Argentina) regulations. Mice were maintained on a $12 \mathrm{~h}$ light/12 h dark cycle (lights on at 7:00 A.M.) with ad libitum access to food and tap water. For some experiments, double-transgenic BAC mice obtained by crossing male Drd2EGFP homozygous mice with hemizygous Drdla-Tomato females were used.

\section{Nigrostriatal lesion}

Under deep surgical anesthesia (isofluorane 1\%), each mouse was mounted in a stereotaxic frame (Kopf Instruments) with a mouse adaptor. 6-OHDA (Sigma-Aldrich) was dissolved in $0.1 \%$ ascorbate-saline at the concentration $4 \mu \mathrm{g} / \mu \mathrm{l}$ (freebase). Mice received $0.5 \mu \mathrm{l}$ injections into the left medial forebrain bundle (MFB) at the following coordinates from bregma: $1 \mathrm{~mm}$ posterior, $1.1 \mathrm{~mm}$ lateral, and $4.8 \mathrm{~mm}$ ventral from dura (Paxinos and Franklin, 2001). Injections were performed at a rate of 0.5 $\mu \mathrm{l} / \mathrm{min}$ using a $300-\mu \mathrm{m}$-diameter cannula attached to a $25 \mu \mathrm{l}$ Hamilton syringe controlled by a motorized pump (Bioanalytical Systems). The injection cannula was left in place for 6 additional minutes before slowly retracting it. Littermates of lesioned mice received an injection of $0.1 \%$ ascorbate-saline in the MFB (sham group). After surgery, mice received special care. Each mouse was weighed daily and received a subcutaneous injection of saline and an enriched diet. This care continued until animals began to regain weight (7-20 d after surgery).

\section{Behavioral tests}

Behavioral testing was performed 3 weeks after 6-OHDA injection on 3 nonconsecutive days during the light phase by an investigator blinded to treatment. All animals were moved from the mouse colony room to a holding room adjacent to the behavioral test room in their home cages at least $1 \mathrm{~h}$ before testing. All mazes and apparatuses were thoroughly cleaned with $10 \%$ ethanol and dried between subjects.

Open-field test. General exploratory activity in a novel open field $(40 \times$ $40 \mathrm{~cm}$ ) was assessed using an automated video-tracking system (Anymaze). Mice were placed in a corner of the arena and left to explore it freely for $15 \mathrm{~min}$. Locomotor activity parameters such as maximum speed, total distance traveled, and number of rotations was calculated offline with Anymaze software.

Cylinder test. Each mouse was placed in a transparent acrylic cylinder (10 $\mathrm{cm}$ in diameter and $14 \mathrm{~cm}$ high) and videotaped for $3 \mathrm{~min}$. Mice responded to the novel environment by standing on their hindlimbs and leaning on the walls of the cylinder with their forelimbs. The number of supporting forepaw placements against the cylinder wall was determined. A lower limit of five wall contacts per session was set to ensure the sensitivity of the test. A limb use asymmetry score was computed by expressing the number of wall contacts performed with the forepaw contralateral to the lesion (right) as a percentage of total wall contacts.

Accelerating rotarod test. Mice were tested concurrently in sets of four using an accelerating rotarod (from 4 to $40 \mathrm{rpm}$ in $3 \mathrm{~min}$; Ugo Basile). The latency to fall from the rod was automatically recorded with a cutoff time of $3 \mathrm{~min}$. Each animal was assessed over 5 trials with $5 \mathrm{~min}$ intertrial intervals in a single day.

\section{In vivo electrophysiological recordings}

Recordings were performed 4-6 weeks after lesion. Mice were anesthetized with urethane $(1.1 \mathrm{~g} / \mathrm{kg}$, i.p.), treated with a local anesthetic in the scalp and pressure points (bupivacaine hydrochlorate solution, $5 \% \mathrm{w} / \mathrm{v}$, $0.1 \mathrm{ml}$, infiltrated), and secured to a stereotaxic frame (Galiñanes et al., 2009) Temperature was maintained between $36^{\circ} \mathrm{C}$ and $37^{\circ} \mathrm{C}$ with a servocontrolled heating pad. Additional urethane was administered as required to maintain anesthesia. Concentric bipolar electrodes (SNE-100; Better Hospital Equipment) positioned in the motor cortex $(+1.2 \mathrm{~mm}$ from bregma, $1.8 \mathrm{~mm}$ from midline and $1.7 \mathrm{~mm}$ below cortical surface) and thalamus $(-1.3 \mathrm{~mm}$ from bregma, $0.8 \mathrm{~mm}$ from midline and $3 \mathrm{~mm}$ below cortical surface) were used to perform electrical stimulation. Another bipolar electrode ( $+1.2 \mathrm{~mm}$ from bregma, $0.8 \mathrm{~mm}$ from the midline and $1.5 \mathrm{~mm}$ below cortical surface) was used to obtain a differential frontal cortex field potential recording (electrocorticogram; $0.1-300 \mathrm{~Hz}$ bandwidth). Juxtacellular recordings of striatal neurons $(0.4-0.8 \mathrm{~mm}$ from bregma, $2.5-3.1 \mathrm{~mm}$ from the midline with a $10^{\circ}$ angle in the coronal plane, and $2-2.5 \mathrm{~mm}$ below the brain surface) were obtained with glass microelectrodes with a tip diameter of 1-2 $\mu \mathrm{m}(14-25 \mathrm{M} \Omega)$ filled with $2 \%$ Neurobiotin (Vector Laboratories) in $0.5 \mathrm{M} \mathrm{NaCl}$. Electrode signal was sent to an Axoclamp 2B amplifier (Molecular Devices) and digitized at $20 \mathrm{kHz}$ using a DigiData $1332 \mathrm{~A} / \mathrm{D}$ board system and digitally filtered (100 Hz to $5 \mathrm{kHz}$, Axoscope 9.0; Molecular Devices). Because MSNs are silent or fire at very low rates, they were detected by evoking orthodromic responses by stimulating the motor cortex every $2 \mathrm{~s}$ at high current intensities $(600-900 \mu \mathrm{A})$ while the recording electrode descended slowly through the striatum. Urethane anesthesia was required to study the functional properties of corticostriatal circuits in the intact brain without interference of sensory, motor, and mood- and taskrelated activities and to allow the use of the high current intensities 
needed to drive MSNs by stimulating the cerebral cortex (see Results). Stimulus-response curves to cortical and thalamic stimulation were obtained with stimuli consisting of $300 \mu$ s square pulses applied every $4 \mathrm{~s}, 40$ times at each current intensity (100-600 $\mu \mathrm{A}, 100 \mu \mathrm{A}$ increments). To label the recorded cells (Pinault, 1996; Zold et al., 2007), positive current pulses $(500 \mathrm{~ms}$ at $2 \mathrm{~Hz}$ ) driving spike discharges (3-15 nA) were delivered through the recording electrode for 5-15 $\mathrm{min}$.

The choice of urethane was based on previous studies showing that many of the alterations observed in the basal ganglia in nonanesthetized patients and animal models of the disease are preserved under urethane anesthesia, including abnormal oscillatory synchronization at different frequencies (Zold et al., 2007, 2012; Ballion et al., 2008; Mallet et al., 2012; Abdi et al., 2015). However, because neuronal responses to afferent stimulation could depend on brain state and type of anesthesia, additional experiments have been performed in head-restrained animals under different doses of isoflurane anesthesia. Mice were implanted with a head plate to allow atraumatic head fixation under ketamine/xylazine anesthesia ( 100 and $10 \mathrm{mg} / \mathrm{kg}$, i.p.) and allowed to recover for $7 \mathrm{~d}$. To perform the electrophysiological recordings, mice were anesthetized with isoflurane $(1 \%)$, treated with a local anesthetic in the scalp, and secured to the head plate. Concentric bipolar electrodes were positioned in the motor cortex and single-unit activity was recorded from the striatum. When striatal neurons showing responses to cortical stimulation as described above were found, stimulus-response curves were performed to cortical stimulation while mice were deeply anesthetized ( $0.5-0.7 \%$ isoflurane). The isofluorane anesthesia $(0-0.2 \%)$ was then reduced and the stimulusresponse curves repeated twice. Finally, the recorded neurons were labeled with Neurobiotine as described above.

The threshold cortical stimulation current was defined as the minimal current driving spike discharges in the recorded neuron during the first $30 \mathrm{~ms}$ after the stimulus in at least one of 20 trials. The cortical stimulation current evoking spikes in $\sim 50 \%$ of the trials was termed $I_{50 \%}$.

\section{Postmortem histology and immunohistochemistry}

At the end of experiments, mice received a high dose of urethane and were transcardially perfused with saline containing heparin (500 IU/L), followed by $4 \%$ paraformaldehyde in phosphate buffer (PB). Brains were dissected out, kept overnight in fixative, and then in 30\% sucrose in PB for $24-48 \mathrm{~h}$ at $4^{\circ} \mathrm{C}$. Coronal sections $(40 \mu \mathrm{m}$ thick) were obtained throughout the substantia nigra, thalamus, dorsal striatum, and frontal cortex using a microtome equipped with a freezing stage and stored free-floating in PBS $0.1 \mathrm{M}$ containing $0.1 \%$ sodium azide at $4^{\circ} \mathrm{C}$ until use. The extent of 6-OHDA-induced nigrostriatal lesion was confirmed by immunohistochemical detection of tyrosine hydroxylase (TH) on sections from the substantia nigra. Briefly, tissue sections were incubated in $0.1 \mathrm{M}$ PBS containing $2 \%$ normal goat serum and $0.3 \%$ Triton X-100 at room temperature and then overnight with rabbit anti-TH $(1 / 1000$; AB152; Millipore). Three rinses in PBS were performed before incubating the sections with anti-rabbit IgG at a working dilution of 1:800 (Vector Laboratories). The antibody-antigen complex was visualized with an avidin-biotin peroxidase complex (Vector Laboratories) and then developed with FITC-streptavidin. Stained sections were mounted on glass sides with anti-fading agent Vectashield (Vector Laboratories). Correct location of stimulation and recording sites was assessed in tissue sections stained with Safranine O (MP Biomedicals). Striatal sections were processed for Neurobiotin labeling to identify juxtacellularly labeled cells. Free-floating sections were incubated in $0.1 \mathrm{M}$ PBS containing $10 \%$ normal goat serum and $0.3 \%$ Triton $\mathrm{X}-100$ at room temperature for $2 \mathrm{~h}$ and then overnight in $0.1 \mathrm{M}$ PBS, $0.3 \%$ Triton X-100, plus FITC-streptavidine (1:500; Sigma-Aldrich) at $4^{\circ} \mathrm{C}$ for experiments performed in Drd1atdTomato mice or in Alexa Fluor 350/405-streptavidine for experiments in Drd1a-tdTomato/Drd2-EGFP mice. High-resolution confocal images were obtained from identified labeled neurons (in green or blue) on an Olympus Fluoview 1000 system using multitrack line switch mode to eliminate spectral bleed-through. Confocal images were assembled in ImageJ and Adobe Photoshop CS5 software to make linear adjustments of contrast and brightness; all adjustments were applied to the entire picture. Confocal images allowed us to identify MSNs by their morphology and to assign them as belonging to direct or indirect pathway (see
Results). Immunofluorescence for interneuron markers was performed as described previously (Taravini et al., 2005). Briefly, sections were rinsed in $0.1 \mathrm{M}$ PBS and then incubated in $1 \%$ BSA with $0.15 \%$ Triton-X for $1 \mathrm{~h}$. This was followed by overnight incubation at $4^{\circ} \mathrm{C}$ with one of the following antibodies: anti-ChAT (1:1000; AB 144P; Millipore), antiparvalbumin (1:3000; \#235; Swant); anti-NOS (1:500 anti-neuronal NOS K20; BD Transduction Laboratories), and anti-NPY (1:500, \#8711; CURE Digested Diseases Research Center, University of California-Los Angeles). After washing, slices were incubated with Alexa Fluor 488conjugated anti-rabbit or anti-mouse secondary antibodies in sections from Drd1a-tdTomato mice and with Cy3-conjugated antibodies in sections from D2 EGFP mice. The proportion of ChAT-, PV-, NOS-, and $\mathrm{NPY}^{+}$cells also expressing td-Tomato or EGFP was estimated from images obtained with a confocal laser scanning microscope. Quantification was performed in $40-\mu \mathrm{m}$-thick sections of dorsal striatum from three mice for each interneuron subtype. DAPI staining was performed in sections $(40 \mu \mathrm{m})$ of dorsal striatum from three double-transgenic mice. Confocal laser scanning microscopy was used, with 11 samples acquired for each section. At least three independent animals were analyzed per histological marker. Regions of interest were defined for each section from the corpus callosum, spanning the entire striatum. The entire region of interest was automatically scanned and composite montages were used for cell-counting purposes. All positive cells in 3- $\mu \mathrm{m}-$ thick optical sections were independently identified in the red and green channel images and counted using ImageJ. Dopaminergic cell depletion in the subtantia nigra was quantified in each animal by immunostaining midbrain coronal sections with anti-TH antibody. High-resolution confocal montages encompassing the entire mediolateral extent of the substantia nigra were acquired. $\mathrm{TH}^{+}$cells were counted by an investigator blinded to treatment using ImageJ. Dopaminergic cell loss was expressed as number of $\mathrm{TH}^{+}$cells in the lesioned side divided by the number of $\mathrm{TH}^{+}$cells in the intact side. At least two anterior-posterior sections were quantified per animal.

\section{Statistics}

Statistical analyses were performed using Statistica (StatSof) or Prism 6 (GraphPad Software). Data are expressed as mean \pm SEM. Depending on the number of experimental groups and factors to be compared, statistical analyses were performed with $t$ tests or one-way, two-way, or repeated-measures ANOVAs followed by post hoc tests when appropriate. Data were tested for normality and homoscedasticity before applying parametric tests. Nonparametric tests were used for comparisons involving proportions and data not suitable to parametric tests. All applied tests were two tailed. After exploratory data analysis, one behavioral feature from each behavioral task was selected to perform multivariate clustering analysis. Ward's method for linkage and square Euclidean distance were used as dissimilarity measures. Relationships among physiological, histological, and behavioral parameters were studied by computing Pearson's and correlations linear regressions. Because multiple correlations/ regressions were computed, significance threshold was adjusted with Bonferroni correction for multiple comparisons.

\section{Results}

\section{Recording and labeling of direct and indirect pathway MSNs in vivo}

To study cortical drive to dMSNs and iMSNs in vivo, we needed to unequivocally identify both MSN classes. Blind juxtacellular recording techniques (Pinault, 1996; Zold et al., 2007) allowed us to label dorsal striatum neurons in vivo in anesthetized DrdlatdTomato/Drd2-EGFP double-transgenic and Drd1a-tdTomato single-transgenic mice (Shuen et al., 2008) and to identify dMSNs and iMSNs postmortem (Fig. $1 a-c$ ). Previous studies have established that the Drd2-EGFP mouse reports nearly all iMSNs (Matamales et al., 2009), but similar studies have not been performed in Drdla-tdTomato mice. In the dorsal striatum of Drd1a-tdTomato/Drd2-EGFP double-transgenic mice, $<2 \%$ of the neurons express both fluorescent proteins, $48 \%$ express only Tomato (dMSNs), 42\% only express EGFP (iMSNs), and $8 \%$ 

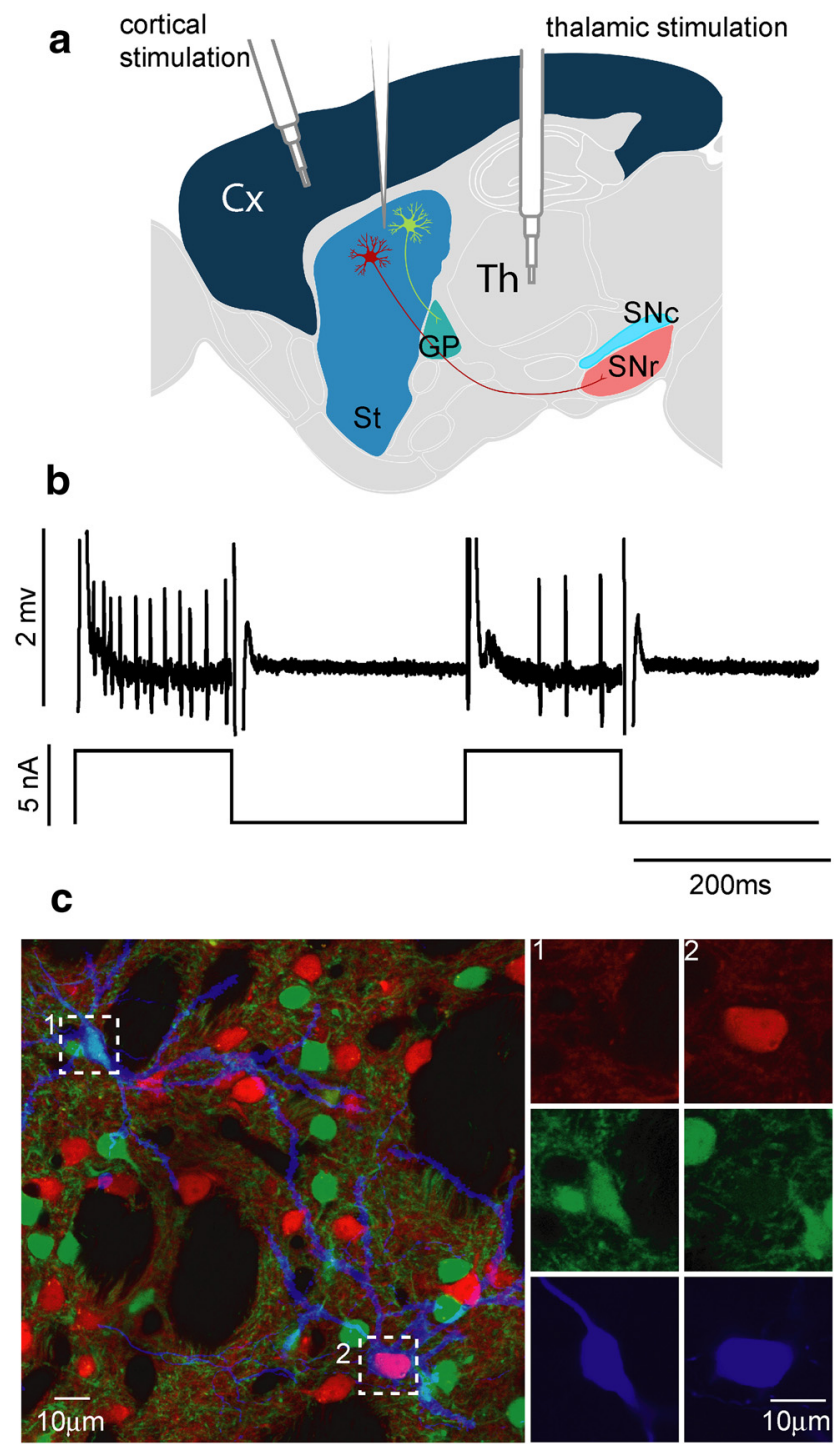

Figure 1. In vivo juxtacellular recording allows to identify dMSNs and iMSNs in transgenic mice. $\boldsymbol{a}$, Schematic representation of electrode positioning for stimulation (cortex and thalamus) and recording (striatum). $\boldsymbol{b}$, Example of cell firing modulation during current injection to label recoded neurons. c, Confocal image from striatum of a double-transgenic mouse showing two neurobiotin-filled neurons (blue). The upper left neuron (1) expressing EGFP but not Tomato was classified as an iMSN. The opposite colocalization pattern in cell 2 led to classification as dMSN. Right, High-magnification confocal images from red (Tomato), green (EGFP), and blue (neurobiotin) channels for each labeled neuron. Scale bars, $10 \mu \mathrm{m}$. Cx, Cortex; Th, thalamus; St, striatum; GP, globus pallidus; SNc, substantia nigra pars compacta; SNr, substantia nigra pars reticulata.

express none (Fig. 2a). These data are consistent with the view that $>90 \%$ striatal neurons are MSNs and suggested that some striatal interneurons may not express the fluorescent markers. Because subsets of striatal interneurons may express D1 or D2 receptors, we have analyzed the MSN selectivity of these transgenic mouse lines by performing immunohistochemical studies to reveal the presence of interneuron markers in coronal brain sections of Drd1a-tdTomato and Drd2-EGFP mice. Except for a few cholinergic interneurons, striatal interneurons do not express the fluorescent markers in these mouse lines (Fig. $2 b$ ). Considering all the above and the fact that striatal interneurons are aspiny (Gerfen and Surmeier, 2011), any blindly recorded spiny neuron not reported by the Drd1a-tdTomato line would very probably be an iMSN. Supporting the above findings, all of the six juxtacellularly labeled cells in double-transgenic Drd1a-tdTomato/Drd2-EGFP mice were MSNs (two Tomato ${ }^{+}$and four Tomato ${ }^{-}$that were $\mathrm{EGFP}^{+}$). Moreover, of 23 labeled neurons in Drd1a-tdTomato mice, nine were Tomato ${ }^{+}$MSNs, 10 were Tomato ${ }^{-}$MSNs, and four were Tomato $^{-}$aspiny interneurons (Fig. $2 c$ ).

\section{Prevalence of the direct pathway in the control striatum}

In slices and in vivo, iMSNs are intrinsically more excitable than dMSNs (Kreitzer and Malenka, 2007; Gertler et al., 2008; Reig and Silberberg, 2014; Maurice et al., 2015); however, excitatory currents generated by pyramidal tract corticostriatal neurons stimulation are higher in dMSNs than iMSNs (Kress et al., 2013). Therefore, the in vivo responses to cortical inputs in different MSN subtypes cannot be predicted from membrane and synaptic properties. To assess cortical drive to dMSNs and iMSNs in control conditions, we studied the responses of $11 \mathrm{dMSNs}$ and 14 iMSNs to increasing intensities of motor cortex electrical stimulation in vivo.

Because MSNs do not fire spontaneously ( 4 of $11 \mathrm{dMSN}$ and 7 of 14 iMSNs) or fire at very low rates ( $n=7$ dMSNs: median 0.06 , range 0.004 to 2.2 spikes/s; $n=7$ iMSNs: median 0.03 , range 0.006 to 0.22 spikes/s; NS, Mann-Whitney test), they were detected by evoking orthodromic responses to motor cortex stimulation at high current intensities (600-900 $\mu \mathrm{A})$ while the recording electrode descended through the striatum. Motor cortex stimulation evoked short-latency spike responses in both cell types (Fig. $2 c$; dMSNs: $9.0 \pm 1.8 \mathrm{~ms}$, iMSNs: $10.5 \pm 3.3 \mathrm{~ms}$; NS), but dMSNs had a significantly lower threshold (Fig. $3 a ; p=$ 0.001, Mann-Whitney test) and higher responsiveness than iMSNs at stimulation currents between 200 and $600 \mu \mathrm{A}$ (Fig. 3b; $p<0.0001$, repeated-measures ANOVA). As expected, Tomato MSNs recorded from Drdla-tdTomato mice (putative iMSNs; $n=10)$ were indistinguishable from iMSNs recorded from double-transgenic mice ( $n=4$; Fig. $3 c$; NS, MSN type effect and interaction, two-way repeated-measures ANOVA). Therefore, blind juxtacellular in vivo recordings allow us to identify dMSNs and iMSNs with high precision in these mouse lines. Moreover, despite being intrinsically less excitable than iMSNs (Kreitzer and Malenka, 2007; Gertler et al., 2008; Reig and Silberberg, 2014; Maurice et al., 2015), recordings that preserve the composition of the intracellular cell milieu show that dMSNs are more markedly activated by cortical inputs in vivo.

Under urethane anesthesia, the membrane potential of corticostriatal neurons and MSNs alternates synchronously between depolarized up and hyperpolarized down states (Stern et al., 1997; Mahon et al., 2001, 2006; Kasanetz et al., 2002, 2006). This alternation results in slow oscillations of the cortical and striatal LFP (Goto and O'Donnell, 2001; Mahon et al., 2001). Although recent studies have revealed membrane potential transitions between depolarized and hyperpolarized states in awake mice both in cortical neurons (Petersen et al., 2003) and MSNs (Reig and Silberberg, 2014), the up state may represent more closely the membrane potential of cortical and striatal neurons in animals performing tasks (Poulet and Petersen, 2008; Sippy et al., 2015). Therefore, we investigated whether the probability of evoking a spike by cortical stimulation depends on the phase of LFP slow oscillations at the time of stimulation. At current intensities evoking spikes in $\sim 50 \%\left(I_{50 \%}\right)$ of the trials, the probability of spike firing was similar in trials in which the LFP oscillation was at its peak or trough at the time of stimulation (Fig. $3 d, e$ ). As expected, $I_{50 \%}$ was significantly smaller for dMSNs than for iMSNs (Fig. $3 f$ ). Therefore, different responses of MSN subtypes to cortical 
a

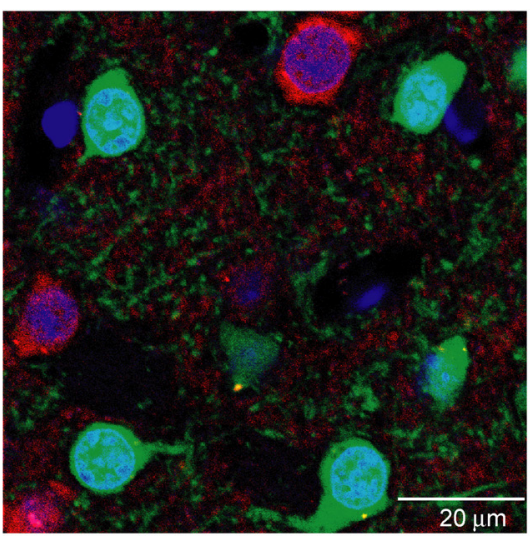

Drd1a - Tom; Drd2- EGFP DAPI

$2 \%$

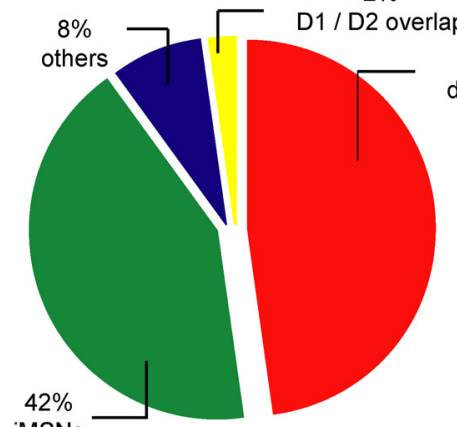

iMSNs

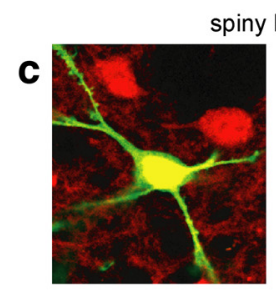

spiny Drd1a (+)

$48 \%$

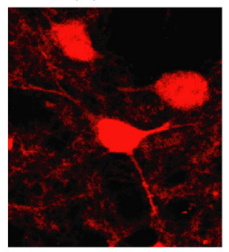

b

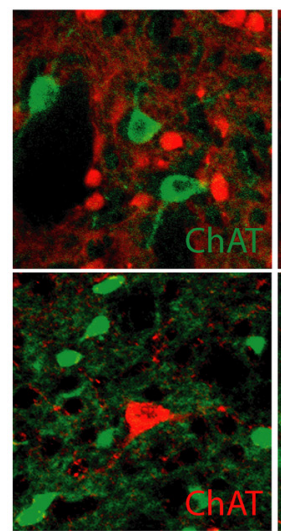

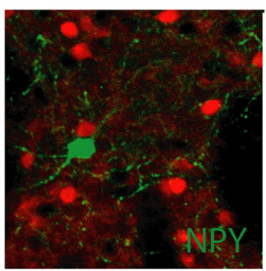
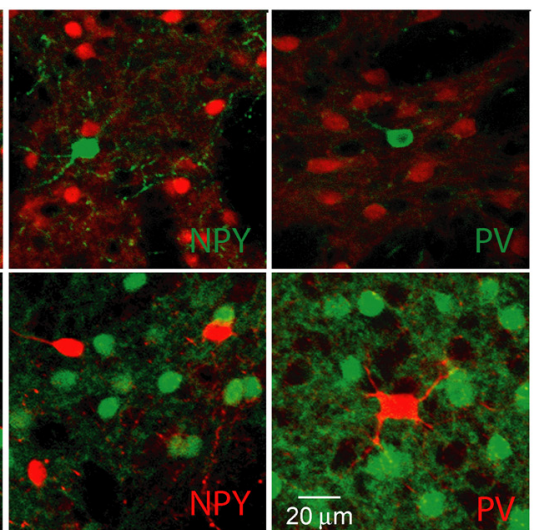

\begin{tabular}{|ccccccc|}
\hline Mice & ChAT & ChAT/D1 & NPY & NPY/D1 & PV & PV/D1 \\
1 & 78 & 1 & 63 & 0 & 90 & 0 \\
2 & 77 & 0 & 109 & 0 & 99 & 0 \\
3 & 90 & 1 & 67 & 0 & 60 & 0 \\
\hline Mice & ChAT & ChAT/D2 & NPY & NPY/D2 & PV & PV/D2 \\
1 & 80 & 8 & 103 & 0 & 93 & 0 \\
2 & 114 & 12 & 150 & 1 & 89 & 0 \\
3 & 56 & 1 & 75 & 0 & 96 & 0 \\
\hline
\end{tabular}

spiny Drd1a (-)

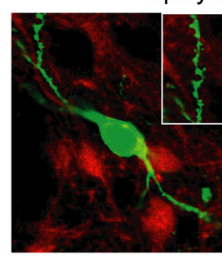

aspiny Drd1a (-)

$\downarrow$

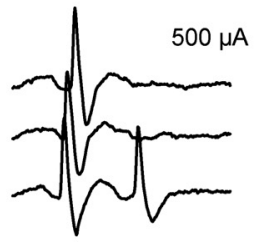

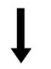
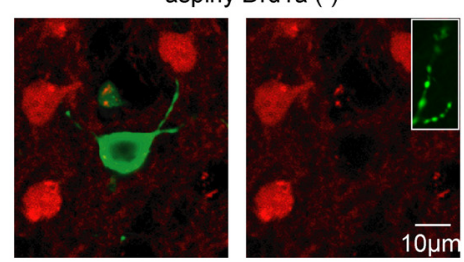

$500 \mu \mathrm{A}$

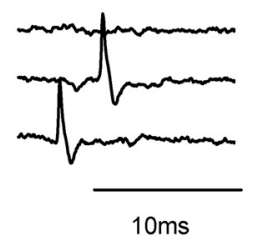

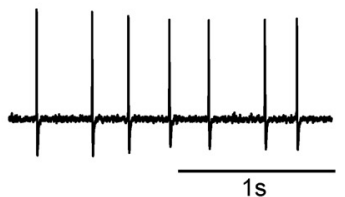

Figure 2. Characterization of BACDrd1a-Tomato, Drd2-EGFP, and Drd1a-tomato/Drd2-EGFP mice. $\boldsymbol{a}$, Top, Confocal image showing DAPI staining (blue channel) of striatum from a Drd1a-tomato/ Drd2-EGFP double-transgenic mice. Bottom, Pie chart showing the relative abundance of Tomato ${ }^{+}$(dMSNs) and EGFP ${ }^{+}$(iMSNs) cells, expressed as the percentage of total DAPI ${ }^{+}$neurons $($small condensed nuclei from glia were excluded). Data are from three mice. $\boldsymbol{B}$, Top, Representative examples of high-magnification confocal images from striatum showing no colocalization of striatal interneuron markers with endogenous labeled cells resulting from the Drd1a-tdTomato (top) and Drd2-EGFP (bottom) transgenes. Bottom, Table summarizing quantitative data for each interneurons marker. C, Neurobiotin-filled neurons (green) after juxtacelullar in vivo recording in Drd1a-tdTomato mice. Confocal images from representative Tomato ${ }^{+}$MSN (left), Tomato ${ }^{-}$MSN (middle; inset depicts dendritic spines at high magnification), and an aspiny Tomato ${ }^{-}$interneuron (right). Representative electrophysiological traces correspond to three trials of cortical stimulation (arrows) or spontaneous activity (interneuron).

stimulation seem not to depend on whether the network is in a depolarized or hyperpolarized state at the time of stimulation.

To further study the response of MSNs to cortical stimulation under different network states, we recorded the response of striatal neurons to cortical stimulation under different levels of isoflurane anesthesia, together with the EEG, in head-restrained animals. Neurons were first recorded under a slow-wave state induced by a relatively high concentration of isoflurane $(0.5-$ $0.7 \%$ ) and then after reducing isoflurane concentration to $0-0.2 \%$. In the latter condition, the EEG desynchronized and the animals sporadically showed movements of the vibrissae and forelimbs consistent with light sedation. A striking difference from urethane was that striatal neurons did not respond or responded weakly to cortical stimulation at $600 \mu \mathrm{A}$ under isoflurane anesthesia (data not shown). By increasing stimulation current to $1 \mathrm{~mA}$, we were able to drive responses in 10 striatal neurons under isoflurane anesthesia. Among them, eight were tdTomato ${ }^{+}$MSNs (dMSNs), two were aspiny interneurons, and none was a tdTomato ${ }^{-}$MSN (putative iMSN). Therefore, the chance of finding an iMSN under urethane anesthesia was $43.5 \%$ while stimulating the cortex at $600 \mu \mathrm{A}$ ( 10 of 23 neurons) and $0 \%$ under $0.5-0.7 \%$ isoflurane, even after cortex stimulation at 
a

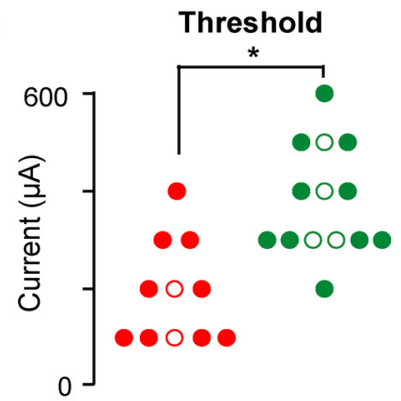

dMSNs iMSNs b

Intensity - response curves

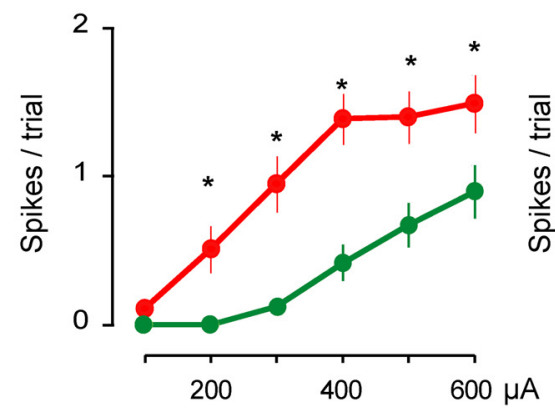

Intensity - response curves

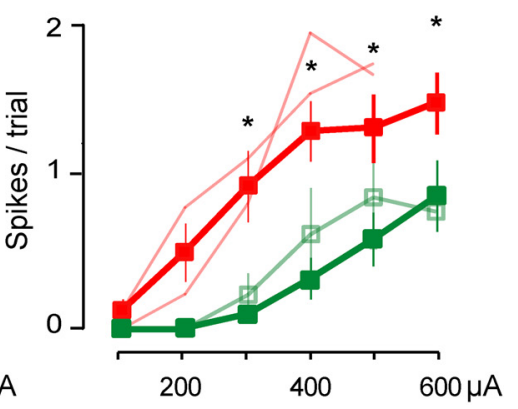

f

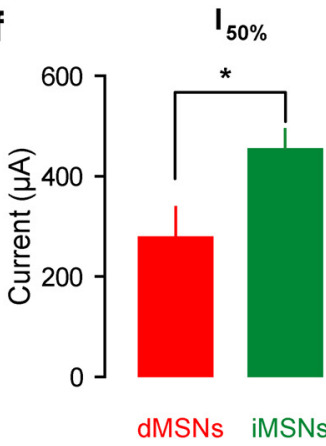

Figure 3. Higher corticostriatal gain of the direct pathway in control transgenic mice. $\boldsymbol{a}$, Threshold current required to induce responses to cortical stimulation in dMSNs ( $n=11$ ) and iMSNs $(n=14)$ recorded from sham Drd1a-tdTomato (red and green circles, respectively) and Drd1a-tdTomato/Drd2-EGFP mice (red and green empty circles, respectively). ${ }^{*} p=0.001$, Mann-Whitney test. $\boldsymbol{b}$, Intensity-response curves to cortical stimulation of dMSNs ( $n=11$; red) and iMSNs ( $n=14$; green) in control mice. ${ }^{*} p<0.05$, Bonferroni post hoc test after significant interaction, repeated-measures ANOVA, $p<0.0001$. Data are mean \pm SEM. $c$, Intensity-response curves to cortical stimulation of MSNs segregated by transgenic mouse line. dMSNs ( $n=9$ ) and putative iMSNs $(n=10)$ recorded from Drd1a-tdTomato mice (red and green squares and lines, respectively) exhibit similar gain to dMSNs ( $n=2)$ and iMSNs ( $n=4)$ recorded from Drd1a-tdTomato/ Drd2-EGFP double-transgenic mice (light red lines and green empty squares, respectively). ${ }^{*} p<0.05$, Bonferroni post hoc test after significant interaction, repeated-measures ANOVA on data from Drd1a-tdTomato mice, $p<0.0001$. Data are mean \pm SEM. $\boldsymbol{d}$, Representative traces showing the responses to cortical stimulation of a dMSN (left) and an iMSN (right) at different phases (peak in gray and trough in black) of LFP slow oscillations. Red bars indicate stimulus onset and artifact. Scale bar, 10 ms. e, Probability of evoking a spike by cortical stimulation does not depend on the phase of the LFP slow oscillation in which the stimulation occurs. This likelihood was measured at current intensities evoking spikes in $\sim 50 \%$ of the trials for dMSNs and iMSNs (nonsignificant main effects and interaction, two-way ANOVA).f, Current intensity evoking spikes in $\sim 50 \%$ of the trials $\left(I_{50 \%}\right)$ was significantly smaller for dMSNs in control animals $(t$ test, $p=0.021)$.

higher intensities ( 0 of 10 neurons identified at $1 \mathrm{~mA}$ stimulation, $p=0.015$, Fisher's exact test). Consistent with the view that isoflurane depressed corticostriatal functional connectivity more markedly than did urethane, the threshold stimulation current for evoking responses in dMSNs was significantly higher under $0.5-0.7 \%$ isoflurane than under urethane $(625 \pm 67 \mu \mathrm{A}, n=8$, and $191 \pm 31 \mu \mathrm{A}, n=11$, respectively, $p<0.05$, Tukey's post hoc test after significant one-way ANOVA). Moreover, although threshold stimulation current decreased to $462 \pm 62 \mu \mathrm{A}$ after reducing isoflurane concentration to $0-0.2 \%$, it remained elevated compared with that observed under urethane $(p<0.05$, Tukey's post hoc test). Therefore, even though it was not possible to compare dMSNs and iMSNs directly under light isoflurane anesthesia, the data support that dMSNs show a higher response probability to cortical stimulation than iMSNs in intact animals.

\section{Unbiased detection of mouse parkinsonism sets aside asymptomatic animals with moderate dopaminergic neuronal loss}

Parkinson's disease is diagnosed by applying well validated clinical criteria. There is no consensus about how diagnosis of parkinsonism should be performed in rodent models. To achieve an unbiased selection of behaviorally impaired animals, we performed multivariate clustering analysis of behavioral data relevant in the context of rodent parkinsonism (Fig. 4). Three weeks after surgery, sham and 6-OHDA-treated mice were studied in a standard open-field test, a cylinder test, and an accelerating rotarod test. Two clear groups emerged from the unsupervised clustering analysis, one containing a mixed population of sham and 6-OHDA-treated mice and another constituted exclusively by 6-OHDA-treated mice (Fig. 4a). The latter subset of 6-OHDA mice $(n=16)$ showed significant impairment in contralateral forelimb use, spontaneous ipsilateral turning, and incoordination during the first trial in the rotarod (Fig. $4 b$ ). In addition, postmortem studies of this symptomatic group revealed an average $85 \%$ reduction of $\mathrm{TH}^{+}$neurons in the substantia nigra and a $82 \%$ reduction of $\mathrm{TH}$ immunostaining in the striatum (Fig. $4 c-$ e). Importantly, the remaining 10 6-OHDA-treated mice could not be distinguished from control animals $(n=10)$ by multivariate clustering based on behavioral parameters (Fig. $4 a, b$ ), but rather showed an intermediate, yet significant, reduction of $\mathrm{TH}^{+}$ cells ( $42 \pm 7 \%, p<0.05$ vs sham and symptomatic mice, Tukey post hoc tests after significant one-way ANOVA: $F_{(2,35)}=67.21$ $p<0.0001$; Fig. $4 e$ ). Further assessment of striatal denervation in both subsets of 6-OHDA mice showed a diffuse loss of TH immunoreactivity in the dorsal striatum (Fig. 4d). A two-way ANOVA comparing the remaining $\mathrm{TH}$ immunoreactivity in the dorsolateral, dorsomedial, ventrolateral, and ventromedial regions of the dorsal striatum across groups (sham, 6-OHDA partial lesion, 6-OHDA severe lesion) showed a significant effect of group $(p<0.0001)$ and nonsignificant effects of region and interaction. Average striatal TH immunoreactivity relative to the 

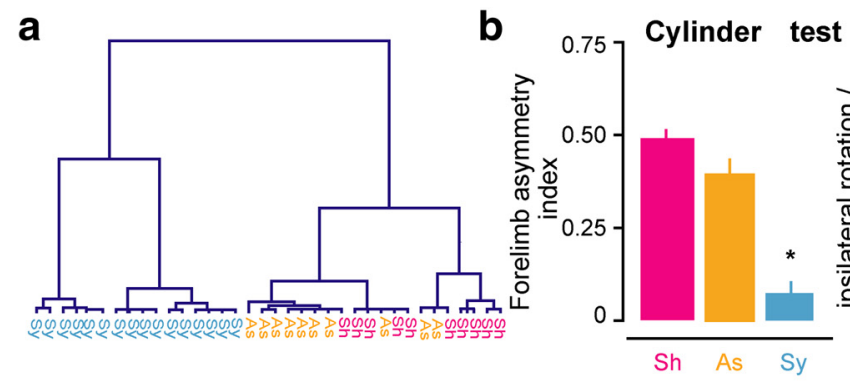

\section{C}

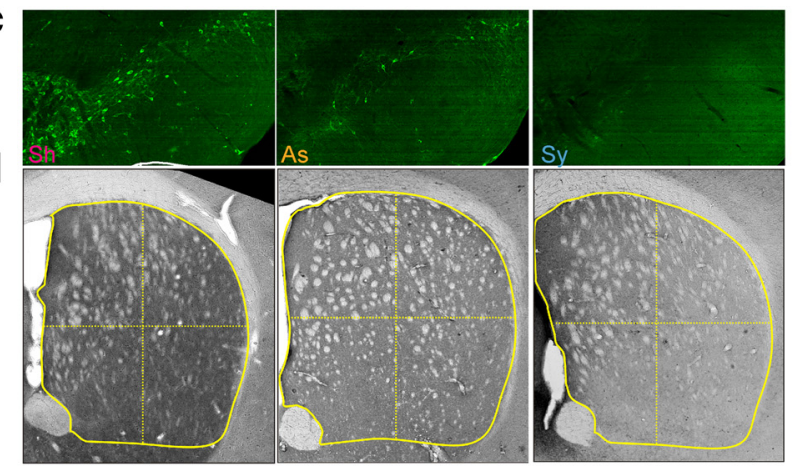

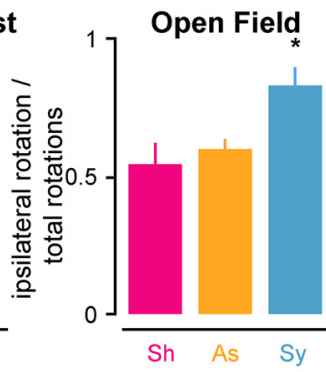

e

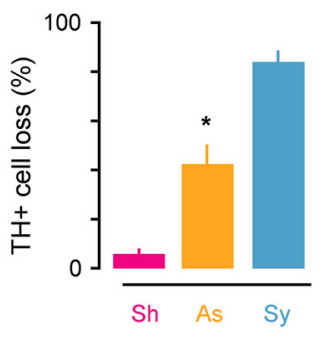

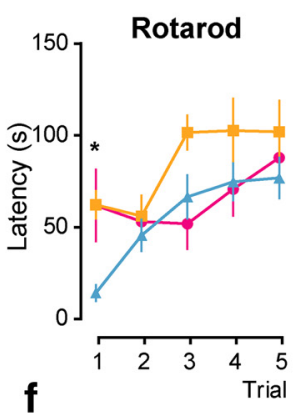

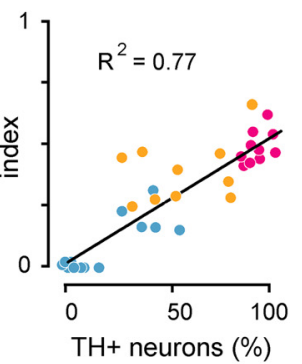

Figure 4. Unbiased separation of asymptomatic from symptomatic 6-OHDA-treated mice. $\boldsymbol{a}$, Dendrogram obtained by unsupervised multivariate clustering analysis of behavioral parameters shown in $\boldsymbol{b}$ defines two clusters. Sy, Symptomatic; As, asymptomatic; Sh, sham. $\boldsymbol{b}$, Behavioral alterations in symptomatic mice. Left, Voluntary use of affected forelimb in the cylinder test $(p<$ 0.0001 , one-way ANOVA followed by Bonferroni post hoc test, ${ }^{*} p<0.05$ vs either sham or asymptomatic mice). Middle, Ipsilateral/total rotations in an open field ( $p=0.012$, one-way ANOVA followed by Bonferroni post hoc test, ${ }^{*} p<0.05$ vs either sham or asymptomatic mice). Right, Incoordination in a motor skill task, the accelerated rotarod ( $p=0.03$, repeated-measures ANOVA interaction, Bonferroni post hoc test, ${ }^{*} p<0.05$ ). Data are mean \pm SEM. c, Confocal reconstructions of substantia nigra illustrating representative lesions of $\mathrm{TH}^{+}{ }^{+}$neurons (green) in Drd1a-tdTomato animals (red: dMSNs terminals in substantia nigra reticulata). $\boldsymbol{d}$, Representative coronal sections of the striatum of sham (left), asymptomatic (middle), and symptomatic (right) mice immunostained with antibodies against TH. White lines show the limits of the quadrants used for regional quantification of TH immunoreactivity. Two-way ANOVA showed a significant effect of group and nonsignificant effects of region and interaction (see text for details). $e$, Percentage of $\mathrm{TH}^{+}$neuron loss in sham, asymptomatic, and symptomatic mice relative to the nonlesioned side. ${ }^{*} p<0.05$ versus sham and symptomatic mice, Tukey post hoc after significant one-way ANOVA: $\left.F_{(2,35)}=67.21 p<0.0001\right) . f$, Linear regression analysis of forelimb use asymmetry as function of percentage $\mathrm{TH}^{+}$cell loss $(p<0.0006)$. Each point represents one animal.

nonlesioned side in the 6-OHDA partial lesion group $(0.59 \pm$ $0.13)$ was significantly smaller than in control animals $(0.99 \pm$ 0.01 ), but significantly higher than in the 6-OHDA severe lesion group $(0.18 \pm 0.06 ; p=0.0001$ for both comparisons, Tukey's post hoc tests). Therefore, the 6-OHDA partial lesion group was considered a model of a preclinical stage of Parkinson's disease and will be subsequently referred to as the asymptomatic group. This is consistent with the widely accepted concept of the need to cross a certain threshold of dopamine depletion for the clinical diagnosis of Parkinson's disease to be possible.

Although the above data show that individual cases can be statistically classified as symptomatic or asymptomatic based on behavioral performance, at the population level, performance in a given test could depend on the degree of nigrostriatal degeneration. Indeed, we found a significant linear correlation between nigrostriatal degeneration and symptom severity. Forelimb use asymmetry $\left(R^{2}=0.77\right.$; slope $=0.5 \pm 0.05, p<0.0006$; Fig. $\left.4 f\right)$ and turning asymmetry $\left(R^{2}=0.24 ; p<0.01\right)$ were both linearly related to the number of remaining $\mathrm{TH}^{+}$neurons in the substantia nigra. Therefore, although there is a correlation between symptom severity and nigrostriatal degeneration, individual cases with moderate lesions may elude diagnosis despite extensive behavioral testing, as is the case in clinical settings.

Functional alterations in corticostriatal connectivity are restricted to the direct pathway in asymptomatic mice

A previous in vivo study emphasized that nigrostriatal lesions induce an imbalance in the response of direct and indirect pathway MSNs to cortical stimulation in the rat (Mallet et al., 2006), but it did not establish whether changes in striatal activity correlate with the occurrence or severity of parkinsonian symptoms. It is still not clear whether striatal activity balance changes when dopaminergic cells are partially depleted. For instance, compensations could maintain a normal striatal activity, thus preventing symptom appearance. Alternatively, the striatal activity imbalance could increase with nigrostriatal degeneration until a normal control of downstream motor structures cannot be sustained any longer, giving rise to the symptomatology. To correlate symptom severity with striatal imbalance, we recorded responses of dMSNs and iMSNs to stimulation of the motor cortex under urethane anesthesia in behaviorally characterized Drdla-tdTomato mice 4-6 weeks after injecting 6-OHDA in the ipsilateral nigrostriatal pathway (Fig. 5a,b). Finally, whether nigrostriatal degeneration alters the response of dMSNs and iMSNs to thalamic afferents in vivo has not been addressed before. Therefore, we also evaluated the response of dMSNs and iMSNs to thalamic stimulation in the same animals.

Intensity-response curves provided direct evidence of opposite changes in the gain of the direct and indirect pathways in symptomatic 6-OHDA-lesioned mice. In control mice, dMSNs and iMSNs showed a maximal response to motor cortex stimulation at currents intensities of 400-600 $\mu \mathrm{A}$. Instead, dMSNs from symptomatic animals were almost completely unresponsive to cortical stimulation at these current intensities (Fig. 5c). Moreover, in symptomatic mice, the response of iMSNs nearly doubled the one obtained in control mice at 400-600 $\mu \mathrm{A}$ (Fig. $5 d$ ). Two-way ANOVA performed on threshold stimulation current (Fig. $5 e ; F_{(2,60)}=14.71, p=0.0001$ ) and response magnitude at $500 \mu \mathrm{A}$ (Fig. $5 f ; F_{(2,56)}=9.90, p=0002$ ) revealed significant 
a
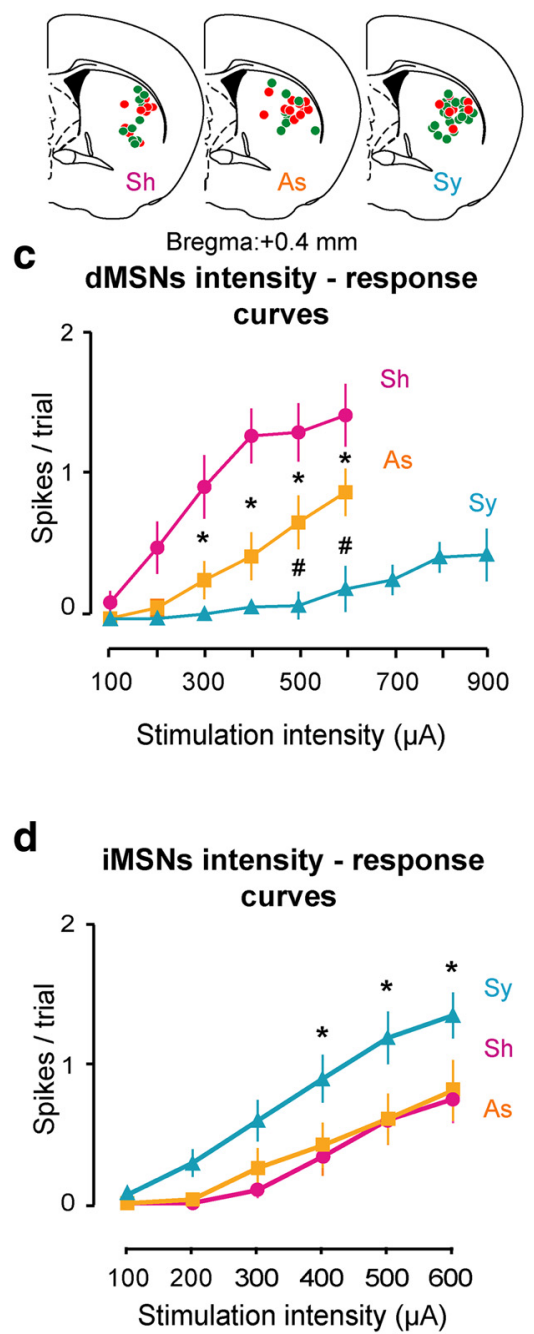

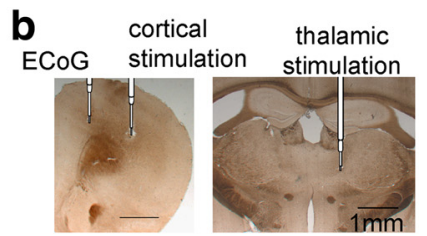

Bregma:+1.7mm Bregma:-1.3mm

e

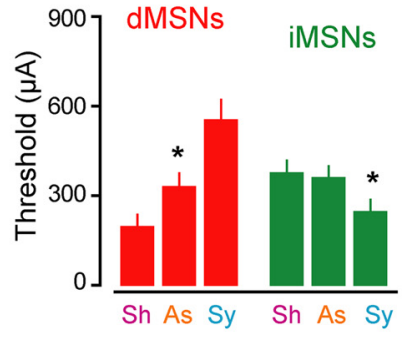

$\mathbf{f}$
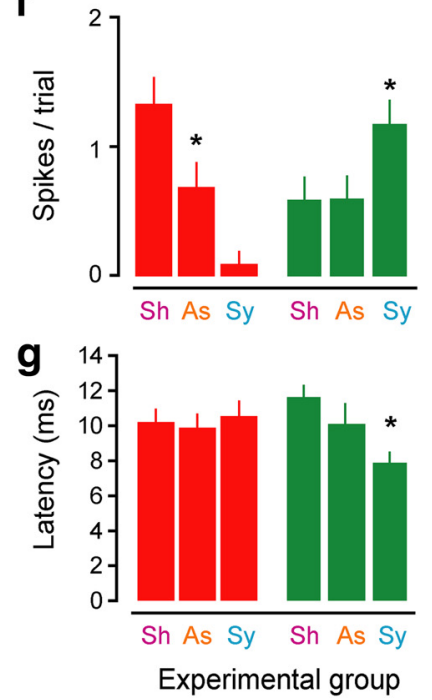

Figure 5. Attenuation of direct pathway functional connectivity after an asymptomatic partial dopaminergic lesion. $\boldsymbol{a}$, Schematic representation of the position of all recorded MSNs in sham, asymptomatic, and symptomatic mice on a plate of Paxinos and Franklin mouse brain atlas (2001). Numbers of neurons recorded per experimental group were as follows: for $\mathrm{dMSNs}, n=9$ in sham, 12 in asymptomatic and $n=7$ in symptomatic mice; for iMSNs, $n=11$ in sham, 8 in asymptomatic, and 20 in symptomatic mice. $\boldsymbol{b}$, Light microscopic images of coronal sections showing the position of the bipolar electrodes in a representative animal. $\boldsymbol{c}, \boldsymbol{d}$, Intensity-response curves to motor cortex stimulation for dMSNs (c) and iMSNs (d) recorded from sham (circles), asymptomatic (squares), and symptomatic (triangles) mice. For dMSNs, repeated-measures ANOVA significant interaction, $p<0.0001$, followed by Bonferroni post hoc tests, ${ }^{*} p<0.05$ asymptomatic versus sham, $\# p<0.05$ symptomatic versus asymptomatic. For iMSNs, repeated-measures ANOVA significant interaction, $p=0.03$, followed by Bonferroni post hoc tests, ${ }^{*} p<0.05$ symptomatic versus both sham and asymptomatic. $\boldsymbol{e}-\boldsymbol{g}$, Threshold (e), gain at $500 \mu \mathrm{A}(\boldsymbol{f})$, and latency $(\boldsymbol{g})$ differences across groups (two-way ANOVA, significant interactions followed by LSD post hoc tests, ${ }^{*} p<0.05$ versus all other groups within cell type). Data are mean \pm SEM.

interactions between group (control, asymptomatic, symptomatic) and MSN subtype, confirming that the direct and indirect pathways show opposite gain changes after nigrostriatal lesions. Importantly, only dMSNs show functional changes in asymptomatic animals (Fig. $5 c$ ). Their responses were significantly diminished to $<50 \%$ of those observed in control mice at $300-600$ $\mu \mathrm{A}(p<0.05$ vs sham, Bonferroni post hoc tests after significant repeated measures two-way ANOVA interaction: $F_{(10,125)}=$ $6.537 p<0.0001)$, but remained significantly elevated compared with those observed in symptomatic animals ( $p<0.05$, Bonferroni post hoc test). In contrast, the intensity-response curve of iMSNs recorded from asymptomatic animals completely overlapped that from control mice (Fig. $5 d$ ). The remaining striatal $\mathrm{TH}$ innervations relative to the nonlesioned hemisphere in the immediate vicinity of the recorded $\mathrm{dM}$ SNs and iMSNs was $0.69 \pm 0.07$ and $0.63 \pm 0.1$, respectively, in asymptomatic animals and $0.27 \pm 0.03$ and $0.26 \pm 0.04$, respectively, in symptomatic animals (significant effect of group, $p<0.0001$, nonsignificant effect of MSN subtype and interaction, two-way ANOVA), further ruling out differences in dopaminergic innervation as a confounding factor. Therefore, changes in the gain of corticostriatal connectivity are restricted to the direct pathway in asymptomatic animals.

We also investigated whether nigrostriatal degeneration affects the latency of the response to cortical stimulation in the two pathways differently. Well timed activations of the direct and indirect pathways are believed to be crucial for action selection (Mink, 1996; Hikosaka et al., 2000; Cui et al., 2013; Schmidt et al., 2013; Jin et al., 2014). Accordingly, a recent study has proposed that, to drive actions, signals carried by the direct pathway must reach the basal ganglia output neurons before the signals carried by the indirect pathway (Schmidt et al., 2013). Our data show that changes in the latency of responses to cortical stimulation are circumscribed to iMSNs of symptomatic animals (Fig. 5g). Although dMSNs and iMSNs from control and asymptomatic mice responded with similar latency to motor cortex stimulation, iMSNs fired significantly earlier than dMSNs in symptomatic mice (Fig. $5 g, p<0.05$, LSD post hoc test after significant two-way ANOVA interaction: $\left.F_{(2,57)}=3.42, p=0.039\right)$. Importantly, the time difference between the beginning and the peak of the response shortened to half in iMSNs of symptomatic animals compared with sham and asymptomatic mice $(p<$ 0.05 , LSD post hoc tests after significant oneway ANOVA, $p=0.0004$; controls: $4.25 \pm$ $0.4 \mathrm{~ms}$; asymptomatic: $3.75 \pm 1.25 \mathrm{~ms}$; symptomatic: $1.58 \pm 0.3 \mathrm{~ms})$. Therefore, functional alterations are not limited to the gain of the pathways, but also involve changes in the timing of their response to cortical input.

Only a fraction of the recorded MSNs also responded to thalamic stimulation. This fraction did not differ between experimental groups for dMSNs $(6 / 11,6 / 12$, and $3 / 7$ in control, asymptomatic, and symptomatic mice, respectively, at $>500 \mu \mathrm{A}$ stimulation current). In contrast, the fraction of iMSNs responding to thalamic stimulation was significantly higher in symptomatic animals than in control mice $(12 / 20$ vs $3 / 14 ; p=0.038$, Fisher's exact probability test) and did not differ between asymptomatic mice (3/8) and the other experimental groups. Unfortunately, we could not analyze the intensity-response curves for these units given the small proportion of neurons showing response to thalamic stimulation. However, a two-way ANOVA performed on threshold stimulation current yielded a significant interaction between experimental group and MSN class $\left(F_{(2,25)}=\right.$ 
$13.93 p<0.0001$; Fig. 6b). Post hoc comparisons showed a significant 2-fold elevation of threshold stimulation current for dMSNs from symptomatic animals compared with control and asymptomatic mice and the opposite (threshold current diminished to half) in iMSNs from symptomatic mice (Fig. 6b).

Overall, our results show that mice that are diagnosed as parkinsonian show functional hyperresponsiveness to cortical and thalamic stimulation of iMSNs, in addition to an attenuation of the responsiveness of dMSNs to both excitatory inputs. Moreover, significant attenuation of dMSN responses to motor cortex stimulation in asymptomatic animals suggests that preclinical dopaminergic compensations may be less effective on dMSNs than on iMSNs and that additional factors may prevent the appearance of symptoms in these animals.

Functional alteration of corticostriatal connectivity is linearly related to forelimb hypokinesia and to nigrostriatal degeneration

It is often assumed that compensations in the remaining dopaminergic neurons are able to maintain a relatively constant physiology of the target cells in the striatum after partial nigrostriatal degeneration (Zigmond, 1997). This would result in nonlinear correlations between degree of nigrostriatal degeneration and functional corticostriatal alterations. However, studies showing an elevation of preproenkephalin A mRNA in the striatum of presymptomatic MPTP lesioned monkeys (Bezard et al., 2001b) and our findings (Fig. 5) suggest that preclinical dopaminergic compensations do not suffice to maintain a normal striatal physiology. Our data show that alterations of corticostriatal connectivity grow linearly with nigrostriatal degeneration, further supporting this conclusion. For dMSNs, threshold stimulation current and spike response to motor cortex stimulation at $500 \mu \mathrm{A}$ (Fig. $7 a, b$ ) were both linearly related to number of $\mathrm{TH}^{+}$neurons in the substantia nigra $\left(R^{2}=0.62, p<0.0001\right.$, and $R^{2}=0.60, p<$ 0.0001 , respectively). Correlations were weaker for iMSNs: significant linear association with $\mathrm{TH}^{+}$neuronal loss was found for the spike response to motor cortex stimulation (Fig. $7 b ; R^{2}=$ $0.17, p=0.0095$ ), but not for threshold stimulation current (Fig. $7 a)$. Moreover, response latency showed a weak linear correlation with lesion extent in iMSNs $\left(R^{2}=0.35, p<0.0002\right)$, but not in dMSNs (Fig. 7c). Finally, because we found that forelimb akinesia was linearly related to degree of striatal degeneration (Fig. 4e), we investigated whether it also correlates with changes in corticostriatal connectivity. Changes of drive from cortex were linearly
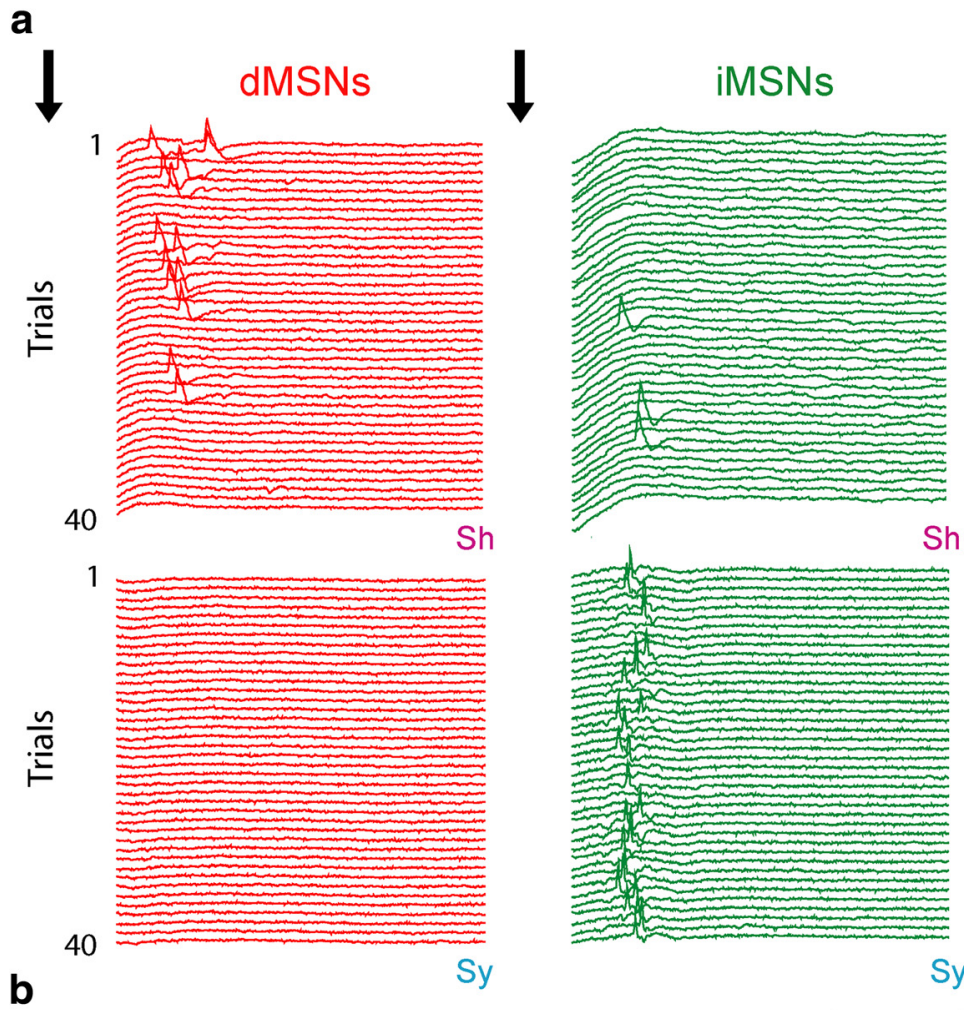

Sy

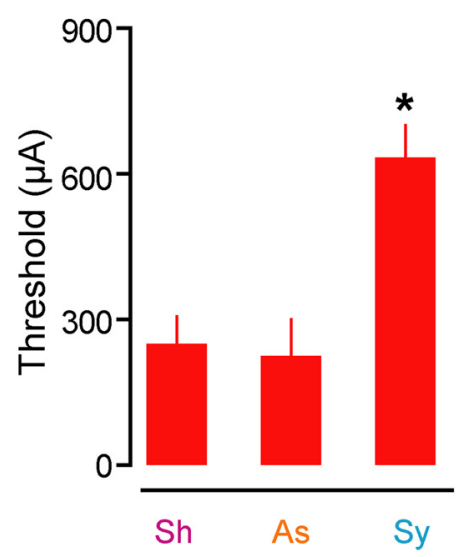

$10 \mathrm{~ms}$

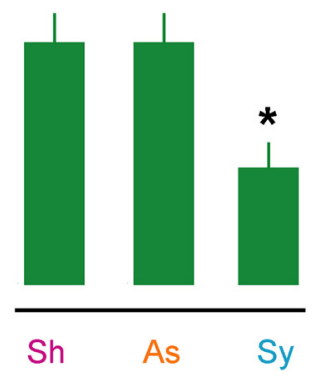

Figure 6. Severe dopaminergic neuron depletion causes thalamostriatal functional disconnection of dMSNs and hyperresponsiveness of iMSNs. $\boldsymbol{a}$, Representative traces showing responses to thalamic stimulation (arrow) in representative dMSNs (left) and thalamic stimulation in dMSNs and iMSNs from sham, asymptomatic, and symptomatic mice. Data are mean \pm SEM $\left({ }^{*} p<0.05\right.$ vs sham, LSD post hoc tests after significant two-way ANOVA interaction, $p<0.0001$ ).

related to forelimb akinesia in both dMSNs and iMSNs (Fig. $7 d-f)$.

Overall, our data suggest that preclinical compensations do not mitigate the effects of nigrostriatal degeneration on the gain of the direct pathway. Moreover, they show a marked correlation between functional changes in corticostriatal connectivity and the severity of forelimb hypokinesia.

\section{Discussion}

We have recorded the response of dorsal striatum dMSNs and iMSNs to stimulation of the motor cortex in control and parkinsonian asymptomatic and symptomatic mice. Our data reveal that, in control animals, dMSNs convey cortical signals more effectively than do iMSNs. Moreover, we found that cortical drive to dMSN loses its predominance after partial nigrostriatal lesions that do not 

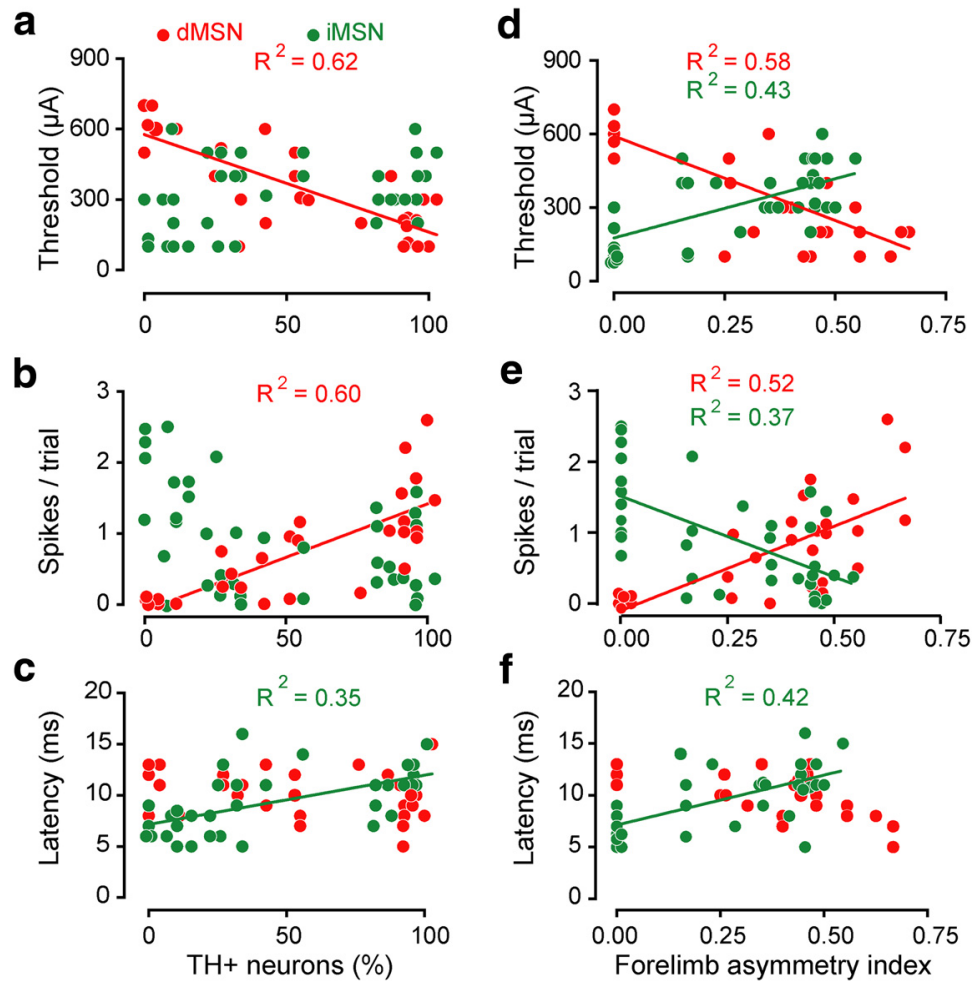

Figure 7. Attenuation of dMSN functional connectivity correlates better with dopaminergic cell loss and behavioral impairment than iMSN hyperresponsiveness. Linear regressions of threshold current $(\boldsymbol{a}, \boldsymbol{d})$, spike response to motor cortex stimulation at 500 $\mu \mathrm{A}(\boldsymbol{b}, \boldsymbol{e})$, and response peak latency at $500 \mu \mathrm{A}(\boldsymbol{c}, \boldsymbol{f})$ on the percentage of remaining $\mathrm{TH}^{+}$cells $(\boldsymbol{a}-\boldsymbol{c})$ or forelimb use asymmetry index $(\boldsymbol{d}-\boldsymbol{f})$ for dMSNs (red) and iMSNs (green). Plotted lines correspond to linear regressions remaining significant after Bonferroni correction for multiple comparisons. Each dot corresponds to a recorded neuron.

produce behavioral impairment. Together with the marked linear relationships observed between functional alterations of dMSNs and the extent of nigrostriatal lesion, our findings suggest that dopaminergic compensations are relatively ineffective at preserving cortical recruitment of the direct pathway. It is important to note that the recordings were performed 5-6 weeks after the partial 6-OHDA lesion, when further dopaminergic compensations were unlikely to occur (Bergstrom and Garris, 2003; Bergstrom et al., 2011). Symptomatic animals show, in addition to a profound disconnection of the direct pathway, an enhanced and faster transmission through iMSNs that was not observed in asymptomatic mice. Finally, instead of compensatory changes that could help to balance the level of excitation of MSNs, thalamostriatal connectivity shows alterations qualitatively similar to those observed in corticostriatal connectivity.

Interventions aimed at scaling the activity of MSNs have generally supported the idea that hyperactivity of the indirect pathway and/or hypoactivity of the direct pathway induce hypokinesia (Durieux et al., 2009, 2012; Bateup et al., 2010; Kravitz et al., 2010; Ferguson et al., 2011). However, there is only one pioneering study that has assessed the activity of dMSNs and iMSNs directly in an animal model of Parkinson's disease, the rat 6-OHDA model (Mallet et al., 2006). That study did not explore asymptomatic animals as we did. Our results are in agreement with those of Mallet et al. (2006), except that we found stronger responses to cortical stimulation in dMSNs than iMSNs in control mice rather than equal responses in both MSN types, and a more profound disconnection of dMSNs in parkinsonian animals. In addition to species differences, the different techniques used for MSN identification could partly account for the discrepancies between the two studies. Here, we could identify every
MSN recorded and get fast-spiking interneuron and dMSN detection rates in control animals that were very close to those expected based on anatomy $(<10 \%$ and 0.9 -fold the number of iMSNs, respectively). Importantly, we could also reliably identify dMSNs with extremely low responses to cortical stimulation in parkinsonian animals, which had not been possible using electrophysiological methods (Mallet et al., 2006). Therefore, we found an unexpected 10-fold decrease of dMSN responsiveness to cortical stimulation in symptomatic mice (Fig. 5), suggesting that many dMSNs are virtually disconnected from the motor cortex in symptomatic animals.

An innovative aspect of our study is the use of unbiased methods to distinguish symptomatic from asymptomatic mice. Studies in the classical 6-OHDA rodent model of Parkinson's disease are usually restricted to animals with extensive nigrostriatal damage, which are selected among those subjected to 6-OHDA injection by arbitrarily setting thresholds of behavioral impairment or nigrostriatal denervation. Therefore, no study has previously assessed the relationship between functional alterations in MSN subtypes and the extent of nigrostriatal degeneration or symptom severity, nor whether functional alterations of MSN subtypes are present in animals with partial lesions that do not induce behavioral symptoms. Our data show that valuable information is gained by studying behaviorally characterized animals with different extents of nigrostriatal degeneration and by using unbiased statistical methods to simulate clinical diagnostic procedures.

A large body of work has led to the concept that compensations in the remaining dopaminergic neurons delay the onset of symptoms in Parkinson's disease by maintaining a relatively normal physiology of striatal neurons (for review, see Zigmond, 1997). Subsequent work revealing molecular adaptations in striatal neurons of presymptomatic MPTP-lesioned monkeys suggested that dopamine homeostasis may be lost before symptom appearance (for review, see Bezard et al., 2003). More recent studies confirm that maintenance of a tonic dopamine level does represent a dopaminergic compensation in asymptomatic animals (Perez et al., 2008, 2010; Sossi et al., 2009; Bergstrom et al., 2011); however, it was still unclear whether the balance of MSN activity remained unaffected in asymptomatic animals. We found that dMSN drive from cortex diminishes linearly with nigrostriatal degeneration and is attenuated in asymptomatic mice. Conversely, the response of iMSNs to cortical stimulation does not differ significantly between asymptomatic animals and controls. We speculate that dopaminergic compensations could sustain sufficient tonic dopamine levels to stimulate high-affinity D2Rs in iMSNs, but may not suffice to maintain the phasic signals required to fully stimulate low-affinity D1Rs in dMSNs (Gonon, 1997; Bergstrom et al., 2011; Dreyer, 2014). After moderate nigrostriatal lesions, the reduction of dopamine uptake compensates for the reduction of release, resulting in "passive stabilization" of tonic dopamine levels (Bergstrom and Garris, 
2003; Dreyer, 2014). Importantly, the concurrent loss of release and uptake sites also results in attenuated phasic dopamine signals after partial dopaminergic lesions (Bergstrom and Garris, 2003; Bergstrom et al., 2011) and reduced stimulation of lowaffinity D1Rs (Dreyer, 2014). Moreover, there is evidence of compensatory upregulation of D2Rs in early Parkinson's disease and presymptomatic MPTP-lesioned monkeys, but regulatory compensations have not been found for striatal D1Rs (Antonini et al., 1994; Turjanski et al., 1997; Kaasinen et al., 2000; Bezard et al., 2001a). Therefore, presynaptic and postsynaptic dopaminergic compensations may be more effective at delaying functional alterations in iMSNs than in dMSNs.

The ultimate pathophysiological mechanisms underlying the observed changes in dMSN and iMSN drive from motor cortex remain to be determined. If corticostriatal connectivity were selectively affected, then thalamostriatal connectivity could have remained unaltered or shown compensatory adaptations preserving the level of excitation of MSNs. Instead, thalamostriatal connectivity shows alterations qualitatively similar to those of corticostriatal connectivity. Changes in MSN membrane properties and excitatory postsynaptic specializations or in intrastriatal inhibition could potentially affect both types of excitatory input. Studies in slices have shown opposite changes of somatic excitability in dMSNs (increase) and iMSNs (diminution) of severely parkinsonian mice (Fieblinger et al., 2014). Because these changes would cause effects opposite to those observed here assessing functional connectivity in vivo, they likely represent compensations that are ineffective against the primary mechanisms of the striatal activity imbalance (Fieblinger et al., 2014). This line of thought suggests that the spine depletion observed in iMSNs (Day et al., 2006; Suárez et al., 2014), which is reversed by chronic L-DOPA administration (Fieblinger et al., 2014; Suárez et al., 2014), may also be compensatory in nature (or could affect inputs other than those of the motor cortex), whereas the enhanced strength of the remaining excitatory synapses (Calabresi et al., 1993; Villalba and Smith, 2011; Fieblinger et al., 2014) and higher excitability of dendrites (Day et al., 2006, 2008; Shen et al., 2007) could be causally related to the strengthened motor cortex drive to iMSNs. Moreover, enhanced dendritic excitability may explain the shortening of the peak latency of iMSNs in symptomatic animals. Regarding dMSNs, the marked functional disconnection observed in vivo correlates with findings from in vitro studies showing decreased excitatory synaptic strength in severely parkinsonian animals (Fieblinger et al., 2014). Although some studies reported a decreased number of spines in dMSNs after 6-OHDA lesions (Villalba et al., 2009; Suárez et al., 2014; Toy et al., 2014), others did not find any differences in spine density (Day et al., 2006; Fieblinger et al., 2014). Because MSNs receive convergent inputs from many cortical areas, it is worth considering whether a reorganization of inputs from nonmotor areas after the lesion accounts for the inconsistent correlation between motor cortex drive and structural changes in dMSNs.

A novel finding of our study is the reduced response latency of iMSNs in symptomatic mice. In control conditions, pyramidal tract and intratelencephalic corticostriatal neurons convey signals to both MSN types (Lei et al., 2004; Kress et al., 2013; Wall et al., 2013) and cortical electrical stimulation induces synchronized peak responses in both MSN types (Mallet et al., 2006; Ballion et al., 2008; Fig. 5). Under conditions in which MSNs are coactivated, feedforward and feedback inhibition shape MSN ensemble activation (Koós and Tepper, 1999; Plenz, 2003; Mallet et al., 2005; Planert et al., 2010; Ponzi and Wickens, 2010; Berke, 2011; Moyer et al., 2014). In contrast, in symptomatic mice, the peak response of iMSNs precedes by $\sim 3$ ms that of dMSNs, which is about the time by which fast-spiking interneuron responses precede MSN responses to cortical stimulation in vivo (Mallet et al., 2005). This suggests that, somehow, iMSNs elude feedforward inhibition in symptomatic animals (see also Mallet et al., 2006). Premature iMSN firing may allow collateral inhibition onto dMSNs to behave as a feedforward circuit in symptomatic mice. Interestingly, feedforward inhibition onto iMSNs increases (Gittis et al., 2011) and feedback inhibition onto dMSNs decreases (Taverna et al., 2008; López-Huerta et al., 2013) after nigrostriatal degeneration. Those changes would oppose rather than promote the MSN activity imbalance, so they might also reflect compensatory adaptations of the striatal circuit (Gittis et al., 2011).

In summary, corticostriatal drive to dMSNs diminishes after partial nigrostriatal damage insufficient to produce significant behavioral impairment. This evolves into an almost complete functional disconnection from motor cortex after more marked nigrostriatal degeneration associated with an evident parkinsonian syndrome. Premature responses of iMSNs to cortical input emerge as a potentially important new finding that may bias intrastriatal competition through collateral inhibition to favor the indirect over the direct pathway.

\section{References}

Abdi A, Mallet N, Mohamed FY, Sharott A, Dodson PD, Nakamura KC, Suri S, Avery SV, Larvin JT, Garas FN, Garas SN, Vinciati F, Morin S, Bezard E, Baufreton J, Magill PJ (2015) Prototypic and arkypallidal neurons in the dopamine-intact external globus pallidus. J Neurosci 35:6667-6688. CrossRef Medline

Antonini A, Schwarz J, Oertel WH, Beer HF, Madeja UD, Leenders KL (1994) [11C]raclopride and positron emission tomography in previously untreated patients with Parkinson's disease: influence of L-dopa and lisuride therapy on striatal dopamine D2-receptors. Neurology 44: 1325-1329. CrossRef Medline

Ballion B, Mallet N, Bézard E, Lanciego JL, Gonon F (2008) Intratelencephalic corticostriatal neurons equally excite striatonigral and striatopallidal neurons and their discharge activity is selectively reduced in experimental parkinsonism. Eur J Neurosci 27:2313-2321. CrossRef Medline

Bateup HS, Santini E, Shen W, Birnbaum S, Valjent E, Surmeier DJ, Fisone G, Nestler EJ, Greengard P (2010) Distinct subclasses of medium spiny neurons differentially regulate striatal motor behaviors. Proc Natl Acad Sci U S A 107:14845-14850. CrossRef Medline

Bergstrom BP, Garris PA (2003) "Passive stabilization" of striatal extracellular dopamine across the lesion spectrum encompassing the presymptomatic phase of Parkinson's disease: a voltammetric study in the 6-OHDA-lesioned rat. J Neurochem 87:1224-1236. CrossRef Medline

Bergstrom BP, Sanberg SG, Andersson M, Mithyantha J, Carroll FI, Garris PA (2011) Functional reorganization of the presynaptic dopaminergic terminal in parkinsonism. Neuroscience 193:310-322. CrossRef Medline

Berke JD (2011) Functional properties of striatal fast-spiking interneurons. Front Syst Neurosci 5:45. CrossRef Medline

Bernheimer H, Birkmayer W, Hornykiewicz O, Jellinger K, Seitelberger F (1973) Brain dopamine and the syndromes of Parkinson and Huntington: clinical, morphological and neurochemical correlations. J Neurol Sci 20:415-455. CrossRef Medline

Bezard E, Dovero S, Prunier C, Ravenscroft P, Chalon S, Guilloteau D, Crossman AR, Bioulac B, Brotchie JM, Gross CE (2001a) Relationship between the appearance of symptoms and the level of nigrostriatal degeneration in a progressive 1-methyl-4-phenyl-1,2,3,6-tetrahydropyridine-lesioned macaque model of Parkinson's disease. J Neurosci 21:6853-6861. Medline

Bezard E, Ravenscroft P, Gross CE, Crossman AR, Brotchie JM (2001b) Upregulation of striatal preproenkephalin gene expression occurs before the appearance of parkinsonian signs in 1-methyl-4-phenyl- 1,2,3,6-tetrahydropyridine monkeys. Neurobiol Dis 8:343-350. CrossRef Medline

Bezard E, Gross CE, Brotchie JM (2003) Presymptomatic compensation in Parkinson's disease is not dopamine-mediated. Trends Neurosci 26: 215-221. CrossRef Medline

Calabresi P, Mercuri NB, Sancesario G, Bernardi G (1993) Electrophysiol- 
ogy of dopamine-denervated striatal neurons. Implications for Parkinson's disease. Brain 116:433-452. CrossRef Medline

Cui G, Jun SB, Jin X, Pham MD, Vogel SS, Lovinger DM, Costa RM (2013) Concurrent activation of striatal direct and indirect pathways during action initiation. Nature 494:238-242. CrossRef Medline

Day M, Wang Z, Ding J, An X, Ingham CA, Shering AF, Wokosin D, Ilijic E, Sun Z, Sampson AR, Mugnaini E, Deutch AY, Sesack SR, Arbuthnott GW, Surmeier DJ (2006) Selective elimination of glutamatergic synapses on striatopallidal neurons in Parkinson disease models. Nat Neurosci 9:251259. CrossRef Medline

Day M, Wokosin D, Plotkin JL, Tian X, Surmeier DJ (2008) Differential excitability and modulation of striatal medium spiny neuron dendrites. J Neurosci 28:11603-11614. CrossRef Medline

DeLong MR (1990) Primate models of movement disorders of basal ganglia origin. Trends Neurosci 13:281-285. CrossRef Medline

Dreyer JK (2014) Three mechanisms by which striatal denervation causes breakdown of dopamine signaling. J Neurosci 34:12444-12456. CrossRef Medline

Durieux PF, Bearzatto B, Guiducci S, Buch T, Waisman A, Zoli M, Schiffmann SN, de Kerchove d'Exaerde A (2009) D2R striatopallidal neurons inhibit both locomotor and drug reward processes. Nat Neurosci 12: 393-395. CrossRef Medline

Durieux PF, Schiffmann SN, de Kerchove d'Exaerde A (2012) Differential regulation of motor control and response to dopaminergic drugs by D1R and D2R neurons in distinct dorsal striatum subregions. EMBO J 31: 640-653. CrossRef Medline

Ferguson SM, Eskenazi D, Ishikawa M, Wanat MJ, Phillips PE, Dong Y, Roth BL, Neumaier JF (2011) Transient neuronal inhibition reveals opposing roles of indirect and direct pathways in sensitization. Nat Neurosci 14: 22-24. CrossRef Medline

Fieblinger T, Graves SM, Sebel LE, Alcacer C, Plotkin JL, Gertler TS, Chan CS, Heiman M, Greengard P, Cenci MA, Surmeier DJ (2014) Cell typespecific plasticity of striatal projection neurons in parkinsonism and L-DOPA-induced dyskinesia. Nat Commun 5:5316. CrossRef Medline

Frank MJ, Samanta J, Moustafa AA, Sherman SJ (2007) Hold your horses: impulsivity, deep brain stimulation, and medication in parkinsonism. Science 318:1309-1312. CrossRef Medline

Galiñanes GL, Taravini IR, Murer MG (2009) Dopamine-dependent periadolescent maturation of corticostriatal functional connectivity in mouse. J Neurosci 29:2496-2509. CrossRef Medline

Gerfen CR, Surmeier DJ (2011) Modulation of striatal projection systems by dopamine. Annu Rev Neurosci 34:441-466. CrossRef Medline

Gertler TS, Chan CS, Surmeier DJ (2008) Dichotomous anatomical properties of adult striatal medium spiny neurons. J Neurosci 28:10814-10824. CrossRef Medline

Gittis AH, Hang GB, LaDow ES, Shoenfeld LR, Atallah BV, Finkbeiner S, Kreitzer AC (2011) Rapid target-specific remodeling of fast-spiking inhibitory circuits after loss of dopamine. Neuron 71:858-868. CrossRef Medline

Gonon F (1997) Prolonged and extrasynaptic excitatory action of dopamine mediated by D1 receptors in the rat striatum in vivo. J Neurosci 17:59725978. Medline

Goto Y, O'Donnell P (2001) Network synchrony in the nucleus accumbens in vivo. J Neurosci 21:4498-4504. Medline

Hikosaka O, Takikawa Y, Kawagoe R (2000) Role of the basal ganglia in the control of purposive saccadic eye movements. Physiol Rev 80:953-978. Medline

Jin X, Tecuapetla F, Costa RM (2014) Basal ganglia subcircuits distinctively encode the parsing and concatenation of action sequences. Nat Neurosci 17:423-430. CrossRef Medline

Kaasinen V, Ruottinen HM, Någren K, Lehikoinen P, Oikonen V, Rinne JO (2000) Upregulation of putaminal dopamine D2 receptors in early Parkinson's disease: a comparative PET study with [11C] raclopride and [11C]N-methylspiperone. J Nucl Med 41:65-70. Medline

Kasanetz F, Riquelme LA, Murer MG (2002) Disruption of the two-state membrane potential of striatal neurones during cortical desynchronisation in anaesthetised rats. J Physiol 543:577-589. CrossRef Medline

Kasanetz F, Riquelme LA, O’Donnell P, Murer MG (2006) Turning off cortical ensembles stops striatal Up states and elicits phase perturbations in cortical and striatal slow oscillations in rat in vivo. J Physiol 577:97-113. CrossRef Medline

Koós T, Tepper JM (1999) Inhibitory control of neostriatal projection neu- rons by GABAergic interneurons. Nat Neurosci 2:467-472. CrossRef Medline

Kravitz AV, Freeze BS, Parker PR, Kay K, Thwin MT, Deisseroth K, Kreitzer AC (2010) Regulation of parkinsonian motor behaviours by optogenetic control of basal ganglia circuitry. Nature 466:622-626. CrossRef Medline

Kreitzer AC, Malenka RC (2007) Endocannabinoid-mediated rescue of striatal LTD and motor deficits in Parkinson's disease models. Nature 445: 643-647. CrossRef Medline

Kress GJ, Yamawaki N, Wokosin DL, Wickersham IR, Shepherd GM, Surmeier DJ (2013) Convergent cortical innervation of striatal projection neurons. Nat Neurosci 16:665-667. CrossRef Medline

Lei W, Jiao Y, Del Mar N, Reiner A (2004) Evidence for differential cortical input to direct pathway versus indirect pathway striatal projection neurons in rats. J Neurosci 24:8289-8299. CrossRef Medline

López-Huerta VG, Carrillo-Reid L, Galarraga E, Tapia D, Fiordelisio T, DruckerColin R, Bargas J (2013) The balance of striatal feedback transmission is disrupted in a model of parkinsonism. J Neurosci 33:4964-4975. CrossRef Medline

Mahon S, Deniau JM, Charpier S (2001) Relationship between EEG potentials and intracellular activity of striatal and cortico-striatal neurons: an in vivo study under different anesthetics. Cereb Cortex 11:360-373. CrossRef Medline

Mahon S, Vautrelle N, Pezard L, Slaght SJ, Deniau JM, Chouvet G, Charpier S (2006) Distinct patterns of striatal medium spiny neuron activity during the natural sleep-wake cycle. J Neurosci 26:12587-12595. CrossRef Medline

Mallet N, Le Moine C, Charpier S, Gonon F (2005) Feedforward inhibition of projection neurons by fast-spiking GABA interneurons in the rat striatum in vivo. J Neurosci 25:3857-3869. CrossRef Medline

Mallet N, Ballion B, Le Moine C, Gonon F (2006) Cortical inputs and GABA interneurons imbalance projection neurons in the striatum of parkinsonian rats. J Neurosci 26:3875-3884. CrossRef Medline

Mallet N, Micklem BR, Henny P, Brown MT, Williams C, Bolam JP, Nakamura KC, Magill PJ (2012) Dichotomous organization of the external globus pallidus. Neuron 74:1075-1086. CrossRef Medline

Matamales M, Bertran-Gonzalez J, Salomon L, Degos B, Deniau JM, Valjent E, Hervé D, Girault JA (2009) Striatal medium-sized spiny neurons: identification by nuclear staining and study of neuronal subpopulations in BAC transgenic mice. PLoS One 4:e4770. CrossRef Medline

Maurice N, Liberge M, Jaouen F, Ztaou S, Hanini M, Camon J, Deisseroth K, Amalric M, Kerkerian-Le Goff L, Beurrier C (2015) Striatal cholinergic interneurons control motor behavior and basal ganglia function in experimental parkinsonism. Cell Rep 13:657-666. CrossRef Medline

Mink JW (1996) The basal ganglia: focused selection and inhibition of competing motor programs. Prog Neurobiol 50:381-425. CrossRef Medline

Moyer JT, Halterman BL, Finkel LH, Wolf JA (2014) Lateral and feedforward inhibition suppress asynchronous activity in a large, biophysicallydetailed computational model of the striatal network. Front Comput Neurosci 8:152. CrossRef Medline

Paxinos G, Franklin K (2001) The mouse brain in stereotaxic coordinates. San Diego: Academic.

Perez XA, Parameswaran N, Huang LZ, O’Leary KT, Quik M (2008) Presynaptic dopaminergic compensation after moderate nigrostriatal damage in non-human primates. J Neurochem 105:1861-1872. CrossRef Medline

Perez XA, Bordia T, McIntosh JM, Quik M (2010) $\alpha 6 ß 2^{*}$ and $\alpha 4 ß 2^{*}$ nicotinic receptors both regulate dopamine signaling with increased nigrostriatal damage: relevance to Parkinson's disease. Mol Pharmacol 78: 971-980. CrossRef Medline

Petersen CC, Hahn TT, Mehta M, Grinvald A, Sakmann B (2003) Interaction of sensory responses with spontaneous depolarization in layer $2 / 3$ barrel cortex. Proc Natl Acad Sci U S A 100:13638-13643. CrossRef Medline

Pinault D (1996) A novel single-cell staining procedure performed in vivo under electrophysiological control: morpho-functional features of juxtacellularly labeled thalamic cells and other central neurons with biocytin or Neurobiotin. J Neurosci Methods 65:113-136. CrossRef Medline

Planert H, Szydlowski SN, Hjorth JJ, Grillner S, Silberberg G (2010) Dynamics of synaptic transmission between fast-spiking interneurons and striatal projection neurons of the direct and indirect pathways. J Neurosci 30:3499-3507. CrossRef Medline

Plenz D (2003) When inhibition goes incognito: feedback interaction be- 
tween spiny projection neurons in striatal function. Trends Neurosci 26: 436-443. CrossRef Medline

Ponzi A, Wickens J (2010) Sequentially switching cell assemblies in random inhibitory networks of spiking neurons in the striatum. J Neurosci 30: 5894-5911. CrossRef Medline

Poulet JF, Petersen CC (2008) Internal brain state regulates membrane potential synchrony in barrel cortex of behaving mice. Nature 454:881-885. CrossRef Medline

Reig R, Silberberg G (2014) Multisensory Integration in the Mouse Striatum. Neuron 83:1200-1212. CrossRef Medline

Schmidt R, Leventhal DK, Mallet N, Chen F, Berke JD (2013) Canceling actions involves a race between basal ganglia pathways. Nat Neurosci 16:1118-1124. CrossRef Medline

Shen W, Tian X, Day M, Ulrich S, Tkatch T, Nathanson NM, Surmeier DJ (2007) Cholinergic modulation of Kir2 channels selectively elevates dendritic excitability in striatopallidal neurons. Nat Neurosci 10:1458-1466. CrossRef Medline

Shuen JA, Chen M, Gloss B, Calakos N (2008) Drd1a-tdTomato BAC transgenic mice for simultaneous visualization of medium spiny neurons in the direct and indirect pathways of the basal ganglia. J Neurosci 28:2681-2685. CrossRef Medline

Sippy T, Lapray D, Crochet S, Petersen CC (2015) Cell-type-specific sensorimotor processing in striatal projection neurons during goal-directed behavior. Neuron 88:298-305. CrossRef Medline

Smith Y, Galvan A, Ellender TJ, Doig N, Villalba RM, Huerta-Ocampo I, Wichmann T, Bolam JP (2014) The thalamostriatal system in normal and diseased states. Front Syst Neurosci 8:5. CrossRef Medline

Sossi V, Dinelle K, Topping GJ, Holden JE, Doudet D, Schulzer M, Ruth TJ, Stoessl AJ, de la Fuente-Fernandez R (2009) Dopamine transporter relation to levodopa-derived synaptic dopamine in a rat model of Parkinson's: an in vivo imaging study. J Neurochem 109:85-92. CrossRef Medline

Stern EA, Kincaid AE, Wilson CJ (1997) Spontaneous subthreshold membrane potential fluctuations and action potential variability of rat corticostriatal and striatal neurons in vivo. J Neurophysiol 77:1697-1715. Medline

Suárez LM, Solís O, Caramés JM, Taravini IR, Solís JM, Murer MG, Moratalla $\mathrm{R}$ (2014) L-DOPA treatment selectively restores spine density in dopa- mine receptor D2-expressing projection neurons in dyskinetic mice. Biol Psychiatry 75:711-722. CrossRef Medline

Taravini IR, Ferrario JE, Delbe J, Ginestet L, Debeir T, Courty J, Murer MG, Gershanik OS, Raisman-Vozari R (2005) Immunodetection of heparinbinding growth associated molecule (pleiotrophin) in striatal interneurons. Brain Res 1066:196-200. CrossRef Medline

Taverna S, Ilijic E, Surmeier DJ (2008) Recurrent collateral connections of striatal medium spiny neurons are disrupted in models of Parkinson's disease. J Neurosci 28:5504-5512. CrossRef Medline

Tecuapetla F, Matias S, Dugue GP, Mainen ZF, Costa RM (2014) Balanced activity in basal ganglia projection pathways is critical for contraversive movements. Nat Commun 5:4315. CrossRef Medline

Toy WA, Petzinger GM, Leyshon BJ, Akopian GK, Walsh JP, Hoffman MV, VučkovićMG, Jakowec MW (2014) Treadmill exercise reverses dendritic spine loss in direct and indirect striatal medium spiny neurons in the 1-methyl-4phenyl-1,2,3,6-tetrahydropyridine (MPTP) mouse model of Parkinson's disease. Neurobiol Dis 63:201-209. CrossRef Medline

Turjanski N, Lees AJ, Brooks DJ (1997) In vivo studies on striatal dopamine D1 and D2 site binding in L-dopa-treated Parkinson's disease patients with and without dyskinesias. Neurology 49:717-723. CrossRef Medline

Villalba RM, Smith Y (2011) Differential structural plasticity of corticostriatal and thalamostriatal axo-spinous synapses in MPTP-treated Parkinsonian monkeys. J Comp Neurol 519:989-1005 CrossRef Medline

Villalba RM, Lee H, Smith Y (2009) Dopaminergic denervation and spine loss in the striatum of MPTP-treated monkeys. Exp Neurol 215:220-227. CrossRef Medline

Wall NR, De La Parra M, Callaway EM, Kreitzer AC (2013) Differential innervation of direct- and indirect-pathway striatal projection neurons. Neuron 79:347-360. CrossRef Medline

Zigmond MJ (1997) Do compensatory processes underlie the preclinical phase of neurodegenerative disease? Insights from an animal model of parkinsonism. Neurobiol Dis 4:247-253. CrossRef Medline

Zold CL, Larramendy C, Riquelme LA, Murer MG (2007) Distinct changes in evoked and resting globus pallidus activity in early and late Parkinson's disease experimental models. Eur J Neurosci 26:1267-1279. CrossRef Medline

Zold CL, Escande MV, Pomata PE, Riquelme LA, Murer MG (2012) Striatal NMDA receptors gate cortico-pallidal synchronization in a rat model of Parkinson's disease. Neurobiol Dis 47:38-48. CrossRef Medline 